\title{
Price competition within and between airlines and high-speed trains: the case of the Milan-Rome route
}

\author{
GRAZIANO ABRATE \\ University of Piemonte Orientale 'A. Avogadro', Department of Economics and Business, \\ Via Perrone 18, 28100 Novara, Italy. \\ GIAMPAOLO VIGLIA \\ Faculty of Management, Bournemouth University, Fern Barrow, Talbot Campus, Poole, \\ Dorset BH12 5BB, UK. E-mail: gviglia@bournemouth.ac.uk. (Corresponding author.)

\section{JAVIER SANCHEZ GARCÍA} \\ Department of Business Administration and Marketing, Universitat Jaume I, Av De \\ Vincent Sos Baynat s/n, 12071 Castello' de la Plana, Spain.
}

\section{SANTIAGO FORGAS-COLL}

Faculty of Economics and Business, Universitat de Barcelona, Av Diagonal 690, 08034 Barcelona, Spain.

In the travel industry high-speed trains and airlines are increasingly competing for passengers, and the diffusion of price optimization based on real time demand fluctuations poses new challenges in the analysis of price competition between operators. This paper presents an analysis of how different competitors simultaneously adjust their prices in the short run. The empirical model accounts for dynamic price variations, exploring both intramodal and intermodal price competition. The results, based on 12,506 price observations, show that intermodal competition presents some kind of asymmetric behaviour, with airlines reacting more than trains to competitors' price changes. The paper concludes with the implications of this heterogeneous behaviour for the tourism and travel industries.

Keywords: competition; airline; rail; pricing; low cost; strategic behaviour 
New dynamic pricing strategies have emerged as a particularly useful tool following advances in new technologies and the growing prevalence of Internet transactions between companies and consumers (Haws and Bearden, 2006). Research on revenue management in the travel industry is quite extensive, especially in the tourism industry (Heo and Lee, 2011; Abrate et al, 2012; Schwartz et al, 2012). Adoption of these technologies depends on a number of internal and external dimensions: temporal; demand and production characteristics; and repurchase intentions.

Aside from internal use of revenue management, research has recently emphasized its relevance to competitors in terms of the interrelated use of revenue management techniques (Narangajavana et al, 2014). Price response systems help operators to identify when competitors have introduced new fares into the market, and to provide recommendations as how to respond to these changes. This automation is essential, considering that there are more than one million fare changes in any given day (Mumbower et al, 2014). Tsai and Hung (2009) clarify the importance of competitive revenue management in practice, however, it remains under-investigated in the literature. This lack of research is evident in the tourism and hospitality industries. Among the scant evidence, Ropero García (2013) showed a strong impact of competitive scenarios on tourist apartments while Rosselló and Riera (2012) focused on the impact of low-cost companies on the traditionally more stable prices of tour operator packages.

In the travel industry, following the liberalization of the airline market in Europe in the late 1990s, the enormous growth of low-cost companies placed great pressure on the established European traditional airlines, reducing profitability of the traditional business model (Dennis, 2007). Furthermore, this competitive arena is now intensified by the growing presence of high-speed rail, at least in Europe (Castillo-Manzano et al, 2015; Delaplace and Dobruszkes, 2015) and China (Jeng and Su 2013). The Milan-Rome route is a perfect example of this new form of competition, with a traditional airline operator, two low-cost operators and two high-speed rail operators. To exemplify the growing importance of the high-speed rail in this market consider that, in the first trimester of 2012, the market share of train over air between Milan and Rome (and vice versa) was 38\%, while in the fourth trimester of 2014 train surpassed air in this route with a 54\% market share (Uvet, 2015).

This paper tests the application of revenue management and price discrimination techniques of different companies (for example, different fares between classes and in different time periods prior to departure). In doing so, it enriches the previous literature by investigating the complex short-run price interrelations among intramodal competition (airlines competing with other airlines as well as train carriers competing with other train carriers - for the same citypair market) and intermodal competition (airlines versus trains).

The empirical application is based on the Milan-Rome route, which offers a suitable case for analysing both intramodal and intermodal competition. The next section presents the conceptual framework, revising the literature on price competition and presenting the hypotheses that will be tested in the empirical part of the paper. The subsequent sections describe the data and the empirical model adopted to test the hypotheses, and then discuss the findings. The last section presents the limitations and conclusions of the paper, with the implications for the tourism and travel industries. 


\section{Conceptual framework}

The framework is based on two strands of literature. First, the article presents the application of revenue management and price discrimination techniques by the travel operators to maximize their revenues. Then, it discusses in detail how competition, and specifically intramodal and intermodal competition, shapes these strategies. In this context the main contribution is on the supply-side, by investigating the factors that influence the price set by operators in the short run.

The travel industry has to cope with heterogeneity, perishability with high sunk costs, cyclical demand and segments with different price elasticities (Bull, 2006). In this context, Dana (1998) claims that since consumers are heterogeneous in both their valuation and their demand uncertainty, a pattern of advance-purchase discounts can increase load factors and profits. This is caused by the low valuations of consumers who are more likely to buy in advance and, from the supply-side, the certainty of allocations of a given number of seats well in advance. Gaggero (2010) explains the non-monotonic intertemporal profile of fares as follows: early bookers show a slightly inelastic demand; middle bookers exhibit the highest demand elasticity; and late bookers book tickets only a few days before departure. This last category is mainly composed of business travellers, with fixed travel dates and destination while the two former categories are composed mainly of standard and tourism customers, who are more flexible and want to plan ahead. While a monopolist can set and maintain high mark-ups for both categories, in an oligopolistic industry, when competition increases, carriers lose this ability: mark-ups associated with the fares paid by the less price-sensitive (business) travellers decrease and align with those of the more price-sensitive standard travellers. Bergantino and Capozza (2015) argue that this situation should be avoided because of the need to preserve, through price discrimination, the mark-ups applied to business travellers.

Aside from advance purchase behaviour, the supply can benefit from offering different attributes to account for the heterogeneity of customers' preferences with respect to travel choice (price, access time, comfort). Although Park and $\mathrm{Ha}$ (2006) mention fares as one of the most important drivers of customers' mode choice and predict a decline in the aviation demand, at least business travellers were shown to be willing to pay more to improve connectivity, access and journey time (O'Connell and Williams, 2005; Jung and Yoo, 2014). It follows that for some segments low prices may not be sufficient to compensate the consumer's additional effort to reach secondary airports and fly at inconvenient time slots, as, for example, a portion of Ryanair's flights requires customers to do. For instance, when looking at revealed preference data provided by travellers, Wang et al (2014) found that the magnitude of elasticity for travel time was higher than the magnitude of elasticity for trip costs in the business segment while the opposite held in the leisure segment. Thus, despite a highly competitive context, the heterogeneity of product valuations across customers can allow many companies to remain profitable (Kim et al, 2009).

Recently, investments in high-speed rail infrastructures have significantly reduced travel time, enhancing mode competition between airlines and trains for the business segment (Ivaldi and Vibes, 2008). Roman et al (2007) inves- 
tigate an example of this type of infrastructure in Europe, the Madrid-Barcelona high-speed line. These authors pay attention to customers' willingness to pay and the level of demand needed to cover the high investment costs of such an infrastructure. Behrens and Pels (2012), examining the consumers' modal preferences on the Paris-London route, highlight how the lack of data for the highspeed train market prevents definitive conclusions to be drawn about the interrelated competition mechanisms. In particular, there is no evidence regarding the intramodal competition between different high-speed train carriers.

The competition between airlines and trains needs to be addressed in light of the application of revenue management techniques, which allow operators to adjust their prices rapidly in the short run. There are two main ways to apply revenue management in practice. The first, generally named the supply- or quantity-based perspective, places special emphasis on inventory capacity allocation. The second, the price-based perspective, uses prices as the primary tactical tool for managing demand. Gallego and van Ryzin (1994) show that a mixture of both pricing and allocation schemes is a practical way to achieve the best revenues and reach optimal results. We claim that the weight of this mixture is different between airlines and high-speed trains. There is growing evidence that airlines apply a mix of quantity- and price-based revenue management to maximize their revenues in a competitive context (Bitran and Caldentey, 2003; Vinod, 2005; Chiang et al, 2007; Luo and Peng, 2007). This phenomenon is explained in Netessine and Shumsky (2005). The basic idea is that, to account for competition, airlines tend to base the allocation of set inventory adopting typical price-based measure. More specifically, they adjust for the demand distribution of each class and account for the prices of competitors. While airlines, especially low-cost airlines, adopt price changes depending on demand and purchase date (Alderighi et al, 2011; Piga et al, 2015), in the high-speed train context various tariffs and classes are set way in advance, favouring more traditional allocations based on the remaining seats for each class.

The above framework above leads us to the following hypotheses.

H1: Travel companies offer advanced-purchased discounts to capture travellers with low valuations.

H2: Both intramodal and intermodal price competition are intense, but only within similar target segments (business travellers and standard travellers). H3: The use of revenue management techniques is different between airline and train industries.

H3a: Due to the number of tariffs and classes, high-speed trains apply mainly quantity-based techniques.

H3b: Airlines react more than high-speed trains to changes in competitors' prices due to revenue management systems built on price-based techniques.

While the core of the analysis is devoted to an investigation of the strategic behaviours of operators in terms of advance booking policies and price reactions to changes in competitors' prices, the regression model includes a control for two other variables that were shown to have a general impact on tariffs: peak load versus off-peak load pricing and week day versus weekend price levels. There is extensive literature on peak-load versus off-peak load pricing strategies 
in transport and tourism (for a review see Pan et al, 2015) and on the variation of tariffs depending on the day in which the travel will take place (Stavins, 2001; Park and Ha, 2006). Nonetheless, it is an interesting research question to assess whether and how operators deal differently with these variables, depending on the customer segment targeted and the mode of transport.

\section{Data and empirical model}

The Milan-Rome route represents an ideal case study for our empirical analysis. It is a route that attracts both business commuters and tourism customers (Holloway and Taylor, 2006). There are several options for getting from Milan to Rome. Aside from driving, five main options are available for a tourist or business traveller: three airline companies (one traditional carrier, Alitalia, and

Table 1. Available fares and travel modes.

\begin{tabular}{|c|c|c|c|c|c|}
\hline \multirow[t]{2}{*}{ Alitalia } & & Comfort Fullflex & Comfort & Easy Flex & Easy \\
\hline & $\begin{array}{l}\text { Number obs } \\
\text { Mean price } \\
\text { SD }\end{array}$ & $\begin{array}{c}1,793 \\
320.37 \\
63.93\end{array}$ & $\begin{array}{c}2,296 \\
238.06 \\
63.19\end{array}$ & $\begin{array}{c}2,311 \\
138.14 \\
30.61\end{array}$ & $\begin{array}{l}1,910 \\
97.87 \\
14.88\end{array}$ \\
\hline Easyjet & $\begin{array}{l}\text { Number obs } \\
\text { Mean price } \\
\text { SD }\end{array}$ & & & $\begin{array}{c}\text { Flexy } \\
602 \\
118.25 \\
43.22\end{array}$ & $\begin{array}{c}\text { Standard } \\
603 \\
53.02 \\
23.51\end{array}$ \\
\hline Ryanair & $\begin{array}{l}\text { Number obs } \\
\text { Mean price } \\
\text { SD }\end{array}$ & & & & $\begin{array}{c}\text { Standard } \\
235 \\
43.42 \\
34.86\end{array}$ \\
\hline Italo & & Base & Economy & Low-cost & Promo \\
\hline Smart & $\begin{array}{l}\text { Number obs } \\
\text { Mean price } \\
\text { SD }\end{array}$ & $\begin{array}{c}1,407 \\
88 \\
0\end{array}$ & $\begin{array}{c}1,329 \\
58 \\
6.24\end{array}$ & $\begin{array}{l}901 \\
45 \\
0.71\end{array}$ & $\begin{array}{l}517 \\
31.6 \\
2.33\end{array}$ \\
\hline Prima & $\begin{array}{l}\text { Number obs } \\
\text { Mean price } \\
\text { SD }\end{array}$ & $\begin{array}{c}1,407 \\
117 \\
0\end{array}$ & $\begin{array}{l}1,397 \\
73.6 \\
7.53\end{array}$ & $\begin{array}{c}1,049 \\
55 \\
0\end{array}$ & $\begin{array}{c}678 \\
48 \\
0\end{array}$ \\
\hline Club & $\begin{array}{l}\text { Number obs } \\
\text { Mean price } \\
\text { SD }\end{array}$ & $\begin{array}{c}1,403 \\
130 \\
0\end{array}$ & $\begin{array}{c}1,365 \\
117 \\
0\end{array}$ & & \\
\hline Frecciarossa & & Base & Economy & & Supereconomy \\
\hline Standard & $\begin{array}{l}\text { Number obs } \\
\text { Mean price } \\
\text { SD }\end{array}$ & $\begin{array}{c}2,423 \\
86 \\
0\end{array}$ & $\begin{array}{c}1,606 \\
51.68 \\
4.46\end{array}$ & & $\begin{array}{c}468 \\
35.35 \\
4.9\end{array}$ \\
\hline Business & $\begin{array}{l}\text { Number obs } \\
\text { Mean price } \\
\text { SD }\end{array}$ & $\begin{array}{c}2,295 \\
116 \\
0\end{array}$ & $\begin{array}{c}2,157 \\
80.57 \\
3.09\end{array}$ & & $\begin{array}{c}1107 \\
49.07 \\
0.85\end{array}$ \\
\hline Executive & $\begin{array}{l}\text { Number obs } \\
\text { Mean price } \\
\text { SD }\end{array}$ & $\begin{array}{c}2,431 \\
200 \\
0\end{array}$ & $\begin{array}{c}1,560 \\
160 \\
0\end{array}$ & & \\
\hline
\end{tabular}


two low-cost carriers, EasyJet and Ryanair) and two high-speed train operators - Trenitalia ('Frecciarossa') and NTV ('Italo'). This setting is suitable for a comprehensive analysis of both intramodal (within airlines and within trains) and intermodal (between airlines and trains) competition.

This study makes use of publicly available information on prices. All available options were monitored in a period aimed at representing a typical week without any special events or festivity (20-26 May 2013). To simulate the customer advance booking process, prices were checked at different points in time, in particular: $1,7,15,30,45$ and 60 days before the date of the journey. For each travel option, all available fares - each characterized by some kind of peculiarity in terms of restrictions or in terms of travel class - were collected.

To reduce biases in the comparison between the different companies, the analysis was limited to the 'one-way' ticket options. ${ }^{1}$ Table 1 shows summary statistics of the main fares available for the five operators, providing a first picture of the revenue management strategies. In general, moving from the left to the right of the table, fares are characterized by tariffs with lower prices but more restrictions in terms of possible ticket changes or refunds as well as other frills (such as snacks). There is some heterogeneity between airlines and trains price differentiation. In the case of Alitalia, the highest fare might be considered as the business class service, because it guarantees more leg space and greater spaces between customers. In the case of trains, the distinction is even clearer, with the class of the service associated with distinct coaches characterized by different quality levels.

An initial consideration of the descriptive statistics provides initial support for hypothesis 3 . Airline prices are characterized by high within-fare variability. On the contrary, the different train fares show a low variability (sometimes even zero), but the quantity of available tickets reduces significantly moving from the left to the right of Table 1. For instance, the super-economy ticket in the Frecciarossa standard class is available on less than $20 \%$ of occasions; likewise, the promo ticket in the Italo smart class is available around one in three times. Thus, train operators prevalently apply quantity-based revenue management strategies.

Overall, Table 1 describes a rather complex set of options available for a typical traveller. To deal with such complexity, we established a set of more standardized alternative travel modes and associated prices $(p)$, ending up with a total number of 12,506 price observations. The eight travel modes are the following.

(a) Traditional carrier airline (Alitalia), standard class, operationalized as the minimum available fare for booking a specific flight with Alitalia.

(b) Traditional carrier airline (Alitalia), business class, operationalized as the Comfort Fullflex fare.

(c) Low-cost airline mode (Easyjet, minimum available fare).

(d) Low-cost airline mode (Ryanair).

(e) Frecciarossa train, standard class, minimum available fare.

(f) Frecciarossa train, business class, minimum available fare.

(g) Italo train, standard class ('Smart'), minimum available fare.

(h) Italo train, business class ('Prima'), minimum available fare.

Individual preferences will drive the ultimate choice of which ticket (if any) to buy. Some people might consider as valid options only the more comfortable business class tickets, while others might just look at the most convenient 
options. Some people might strictly prefer travelling by train (or by plane); others might be more flexible. By looking at dynamic price evolutions in the above categories, the main research question is whether (and how much) an operator cares about price variations in competing segments when defining its revenue management strategy. Implicitly, it is reasonable to expect a higher degree of price correlations when customers exhibit a higher degree of substitutability between the alternative options.

We propose a model in which the price depends on the day of the week, the hour of the day, the booking time and the competitors' prices, and in which all these covariates interact with the travel modes defined above, in order to examine specific price patterns. More specifically:

$$
\begin{aligned}
p & =\sum_{n} \beta_{n} * \text { Type }_{n}+\sum_{j, n} \beta_{j n} * \text { Weekday }_{j} * \text { Type }_{n}+\sum_{l, n} \beta_{l n} * \text { Hour }_{l} * \text { Type }_{n} \\
& +\sum_{m, n} \beta_{m n} * \text { Adbook }_{m} * \text { Type }_{n}+\sum_{r \neq n} \beta_{r n} * \text { Compprice }_{r} * T_{y p e_{n}},
\end{aligned}
$$

where the dependent variable $(p)$ is expressed in logarithm; Type indicates a set of eight dummies characterizing each of the eight travel modes (Alitalia standard and business, Easyjet, Ryanair, Frecciarossa standard and business, Italo standard and business); Weekday indicates the day of the week (seven dummies); Hour indicates a set of five dummies characterizing the different time slots during the day $(6-10 \mathrm{am} ; 10 \mathrm{am}-1 \mathrm{pm} ; 1 \mathrm{pm}-4 \mathrm{pm} ; 4 \mathrm{pm}-7 \mathrm{pm}$; later than $7 \mathrm{pm}$ ); Adbook indicates a set of six dummies defined according to the number of days of advance booking before travelling (for example, 60 days means that the price refers to a ticket booked 60 days in advance); Compprice indicates the minimum price available (in logarithm) for each of the alternative travel Type within the same time slot (Hour). Thus, it reflects the presence of price promotions in the potentially competing segments. ${ }^{2}$

The estimation strategy is based on a random effect panel data specification. In particular, we aim to capture unobserved heterogeneity across each specific train or flight departure (and across different travel categories within the same train/flight departure). One major potential source of unobserved heterogeneity is related to the occupancy rate: for example, we do not observe how many passengers have travelled in business class on the 6 am Frecciarossa train. The time dimension of the panel is instead given by the six advance booking options simulated for each journey (that is, by the fact that price information for each journey was retrieved at $1,7,15,30,45$ and 60 days before the date of the journey).

Following our hypotheses development, the main interest is measuring $\beta_{m n}$, the impact of advance booking on prices (H1), and $\beta_{r n}$, the relations between the prices of competitors ( $\mathrm{H} 2$ and $\mathrm{H} 3$ ). While doing so, the regression model includes a control for possible asymmetric behaviour across operators between weekdays and weekends $\left(\beta_{j n}\right)$, and variations in the transport option in peak hours and off-peak hours $\beta_{j n}$.

\section{Results and discussion}

Table 2 presents the estimated coefficients of the random effect panel regression $(R$-squared: overall $=0.9250 ;$ within $=0.7226$; between $=0.9584)$. First, 


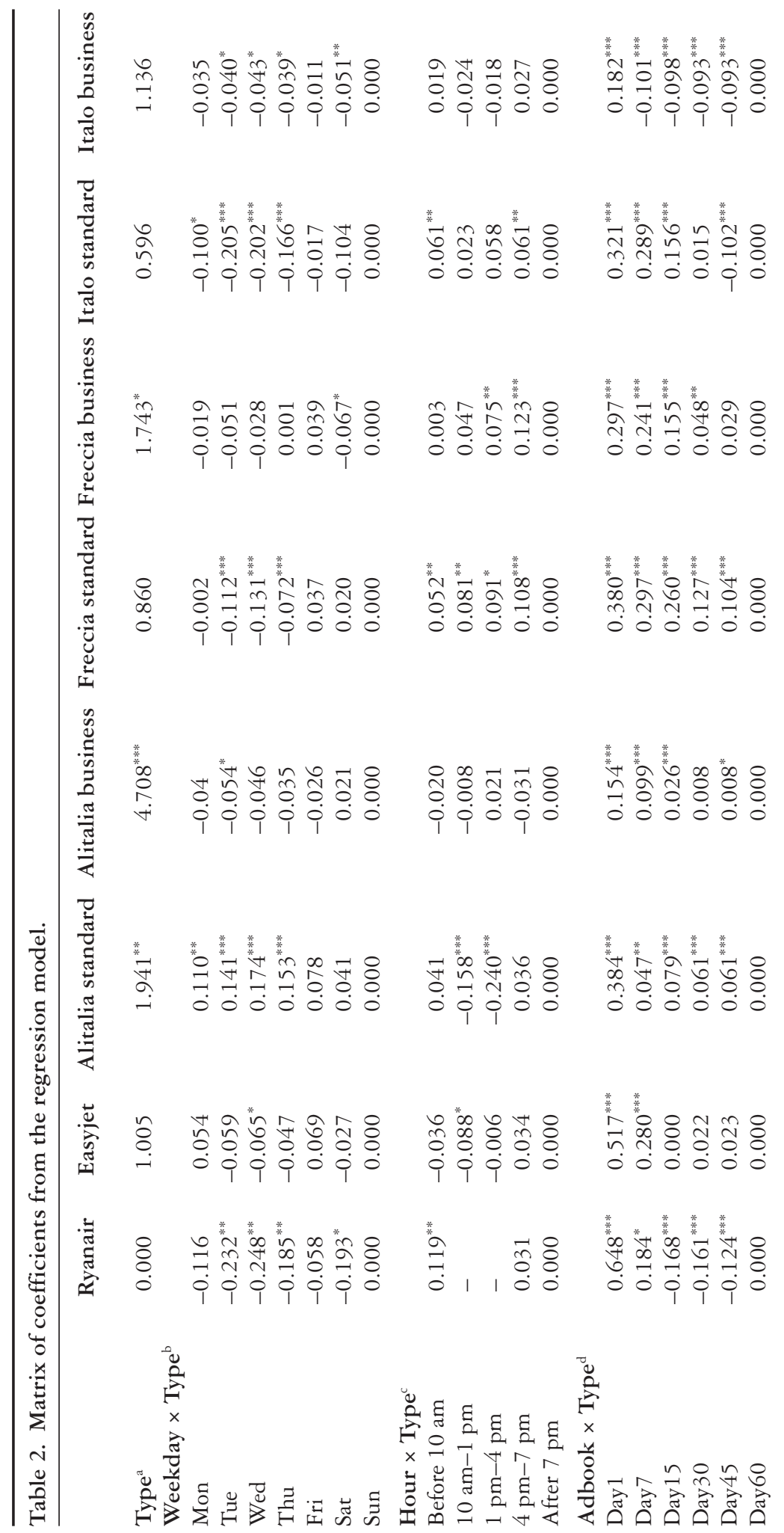




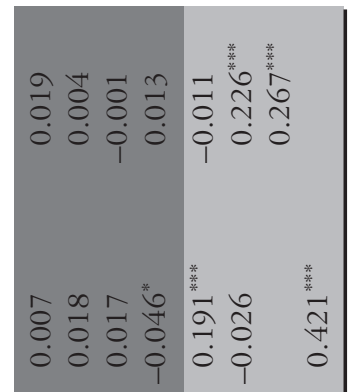

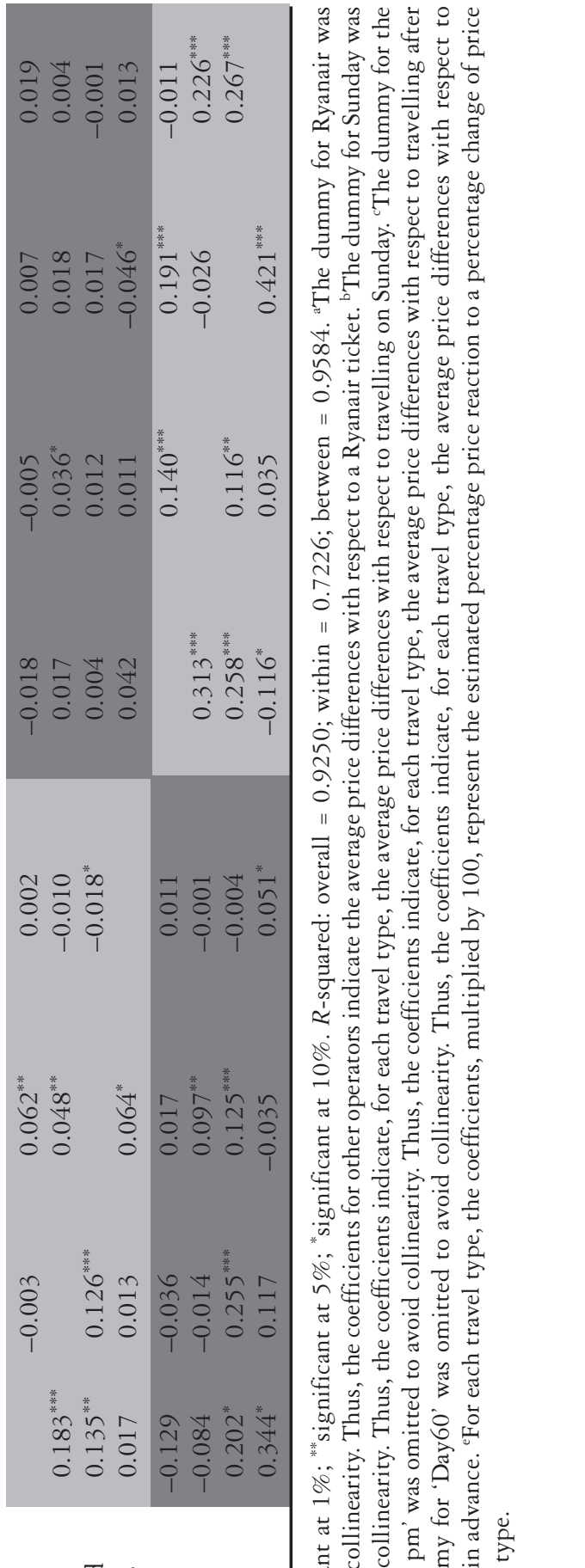

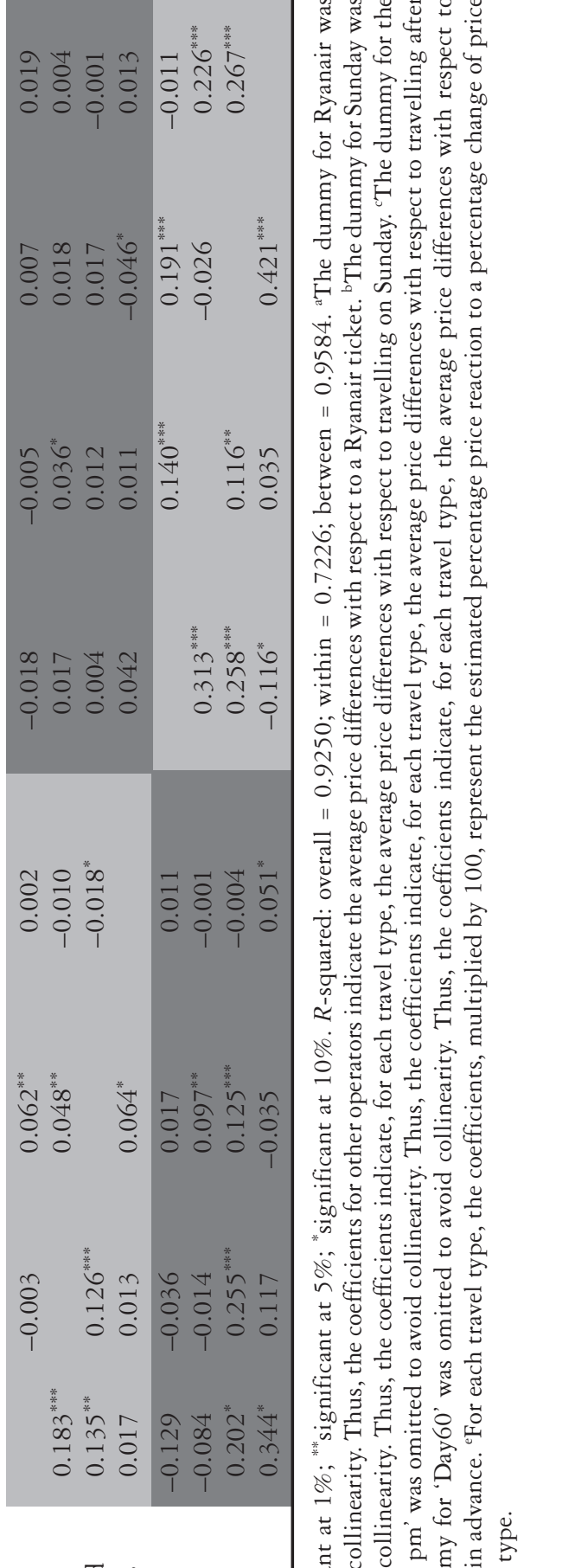

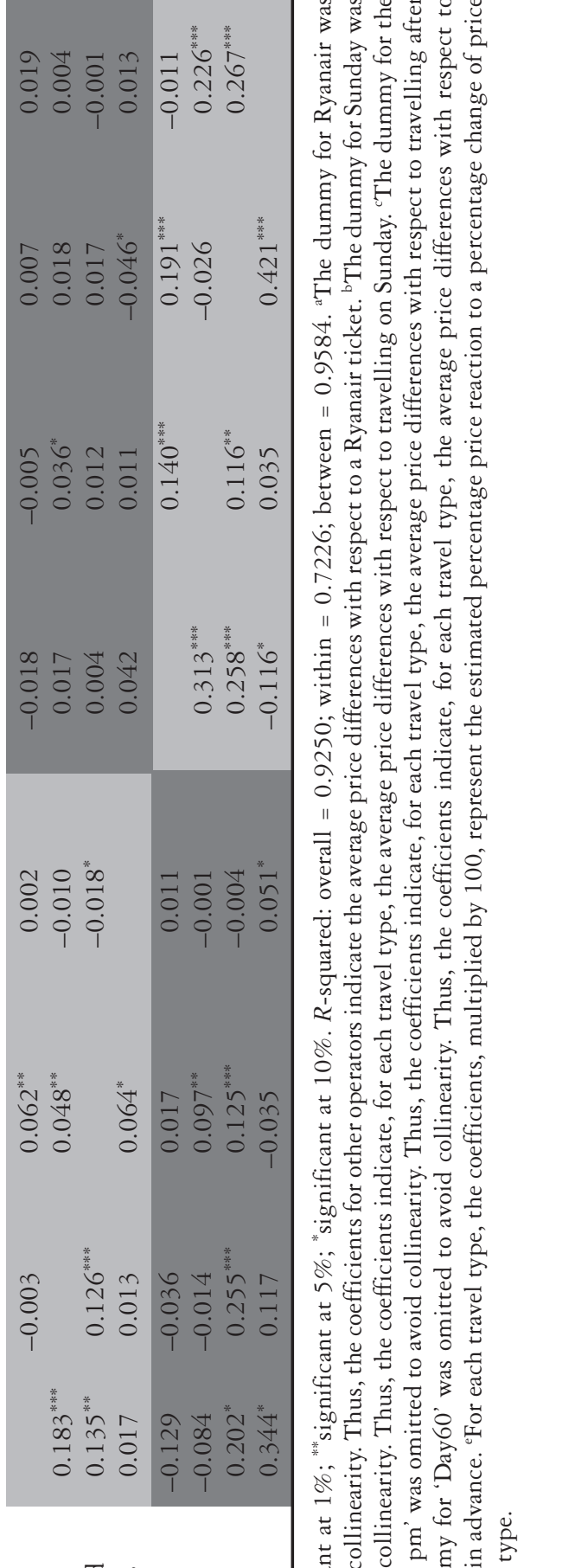

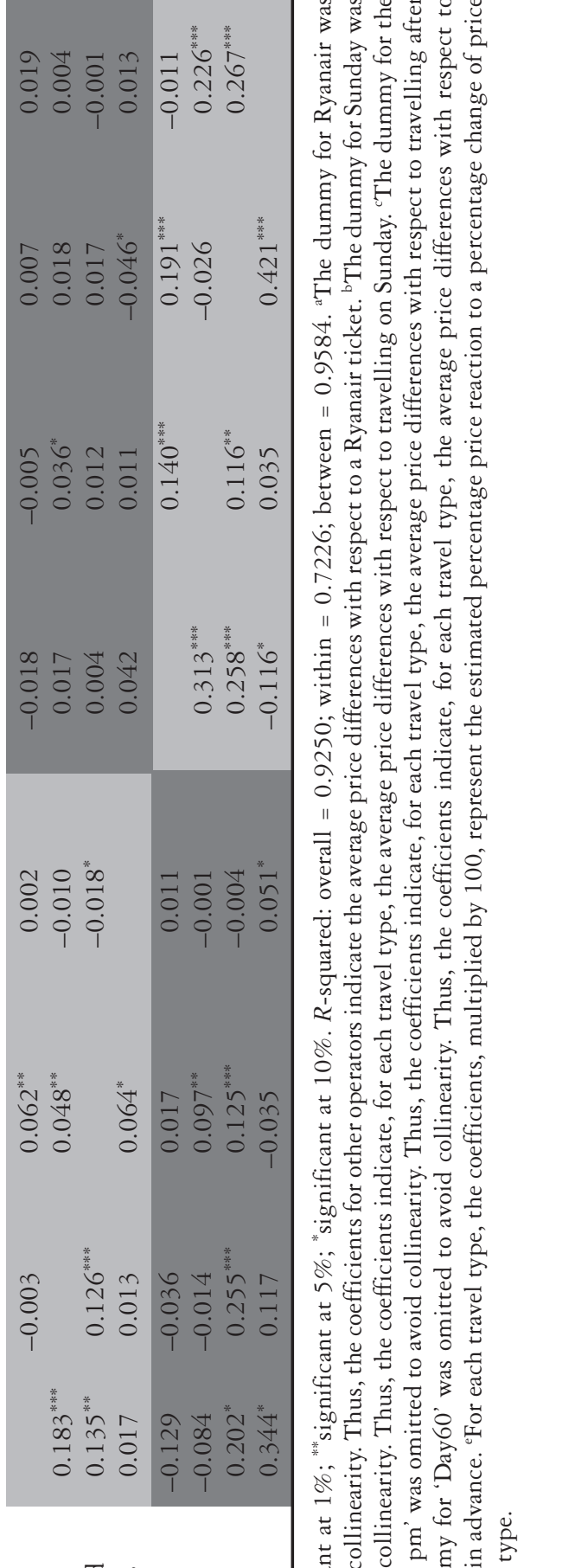

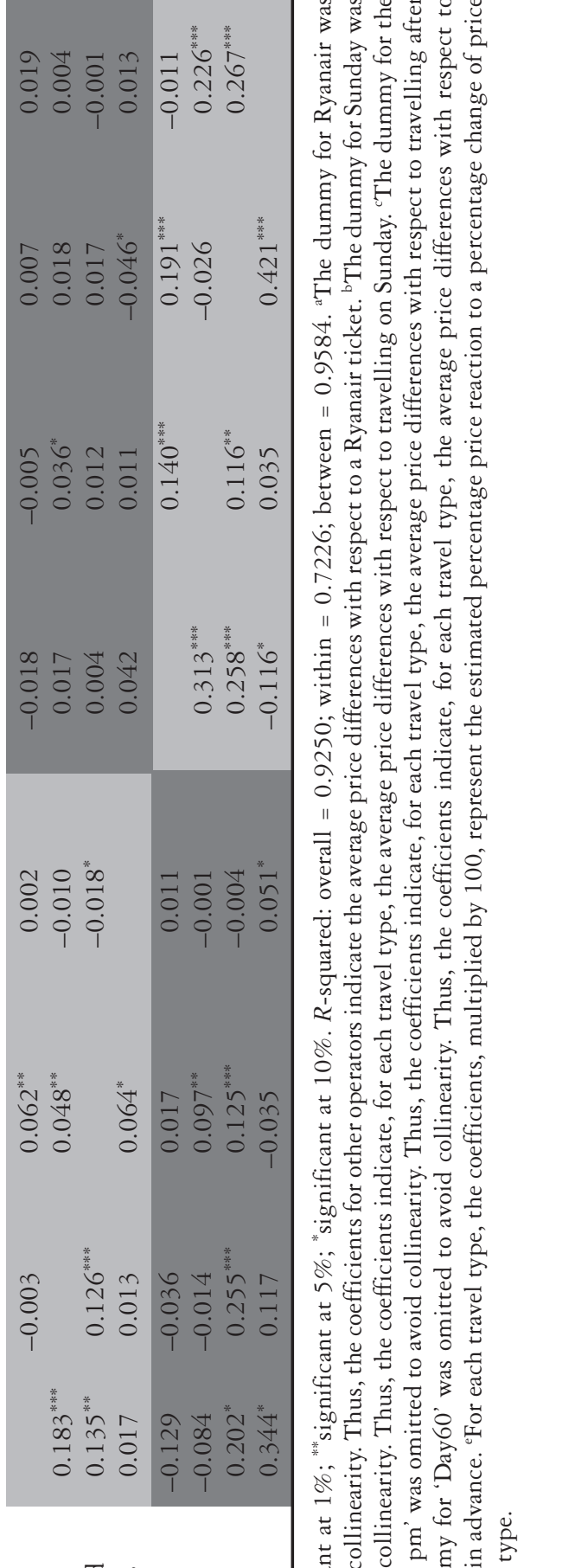

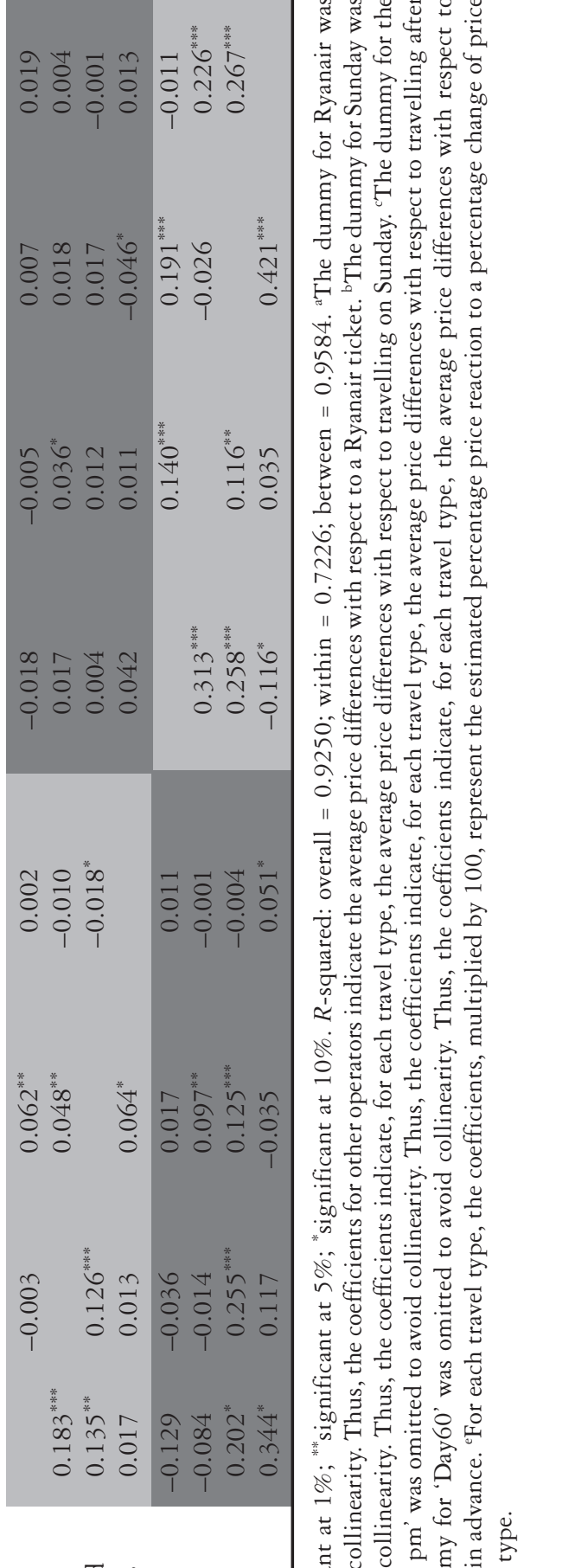

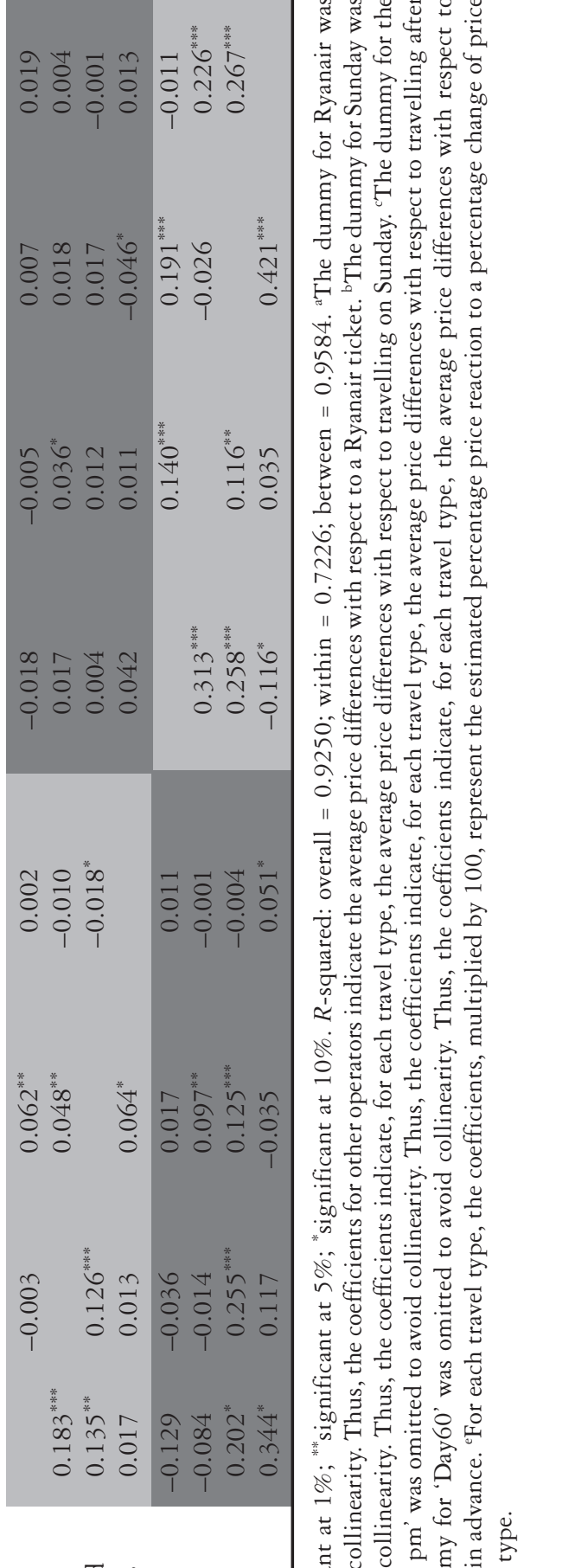

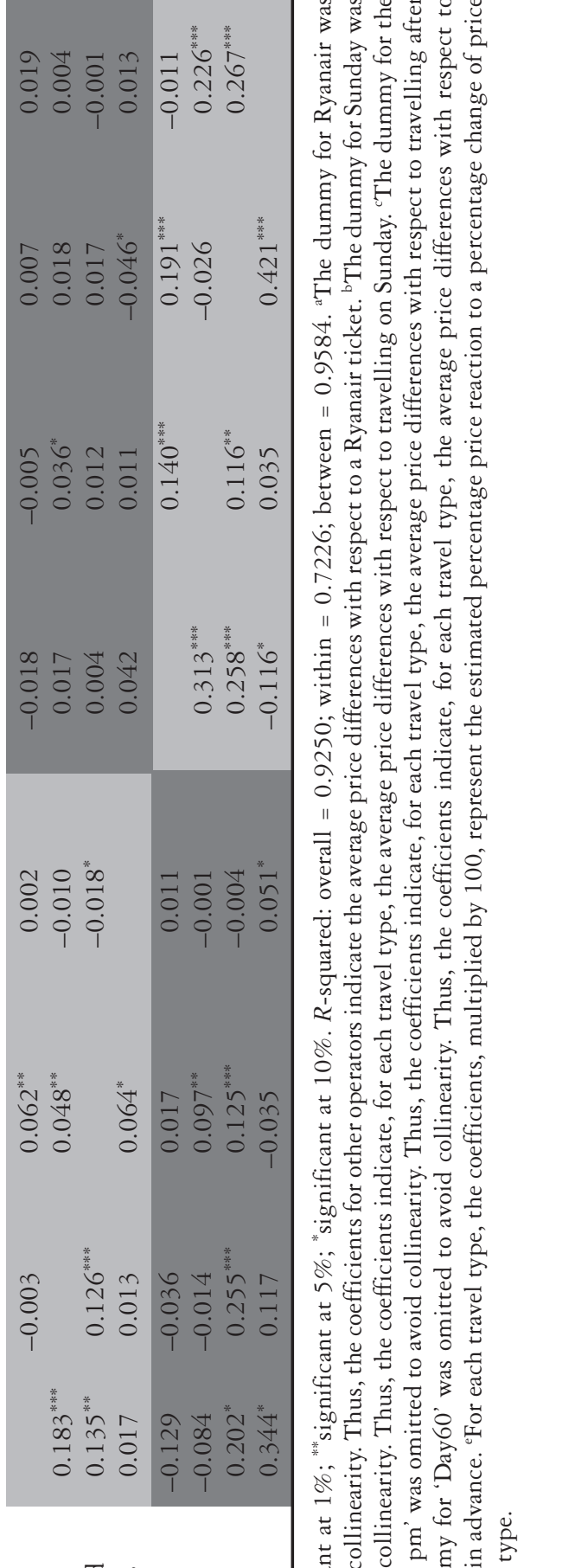

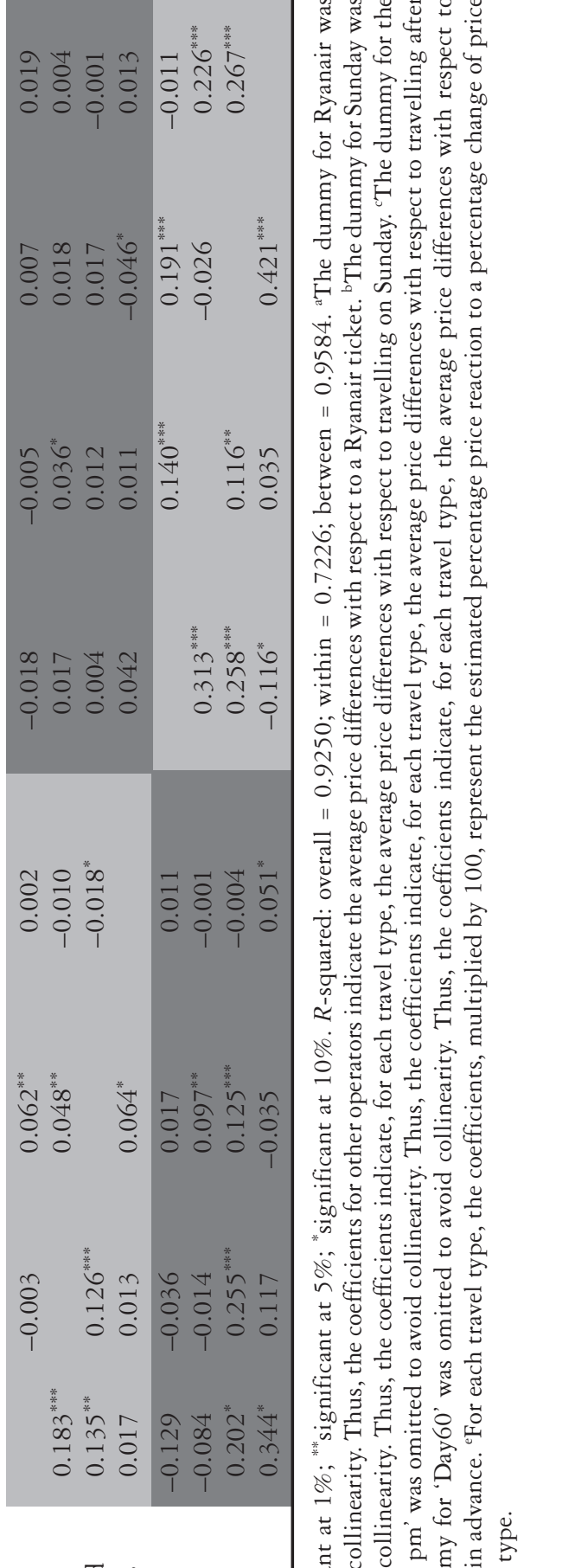

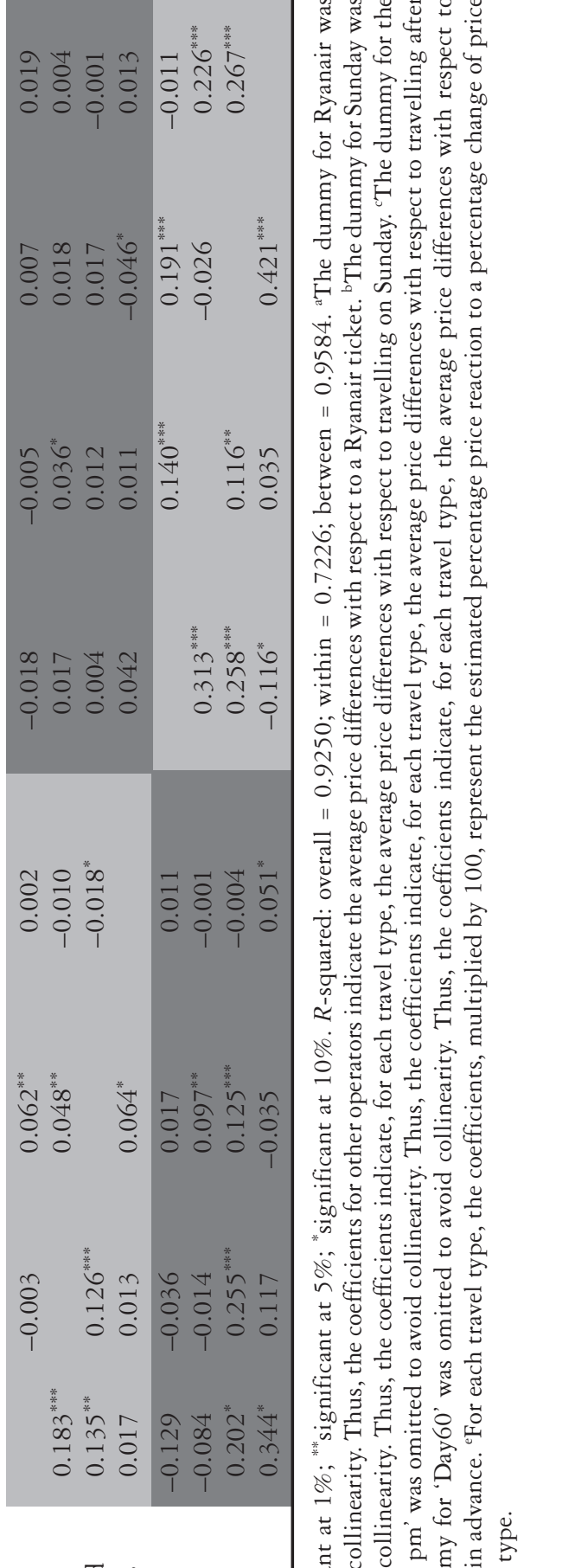

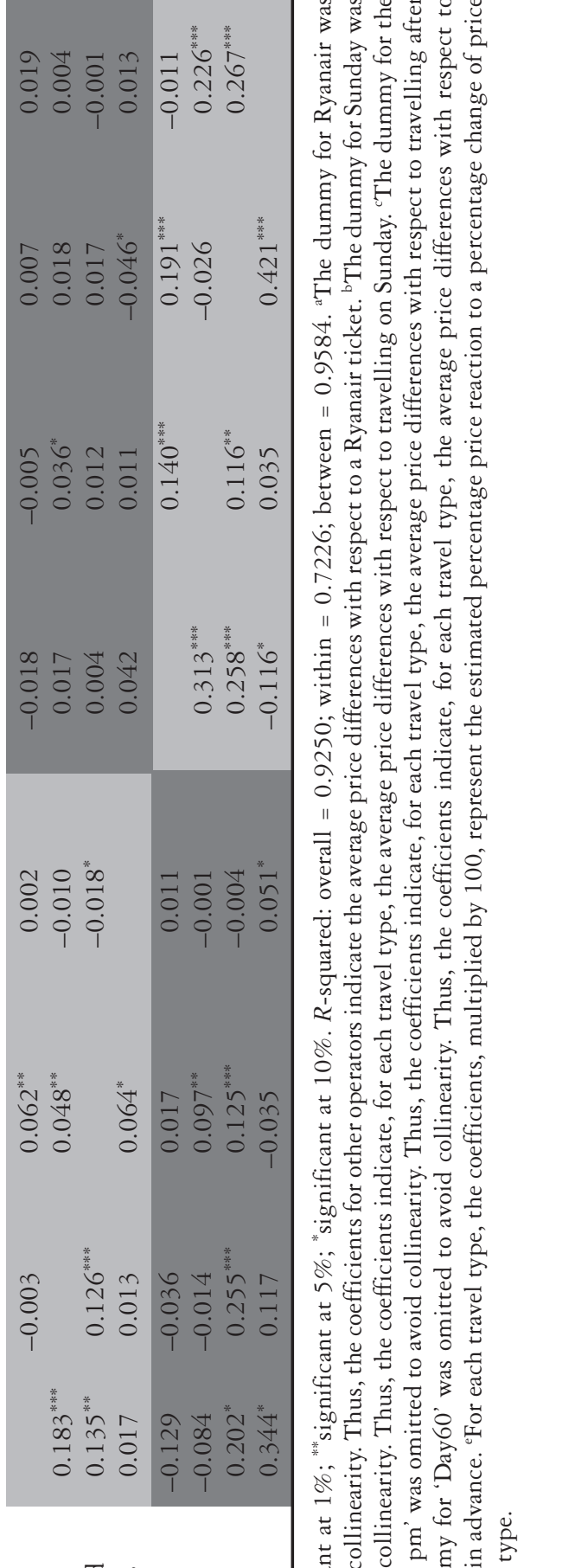

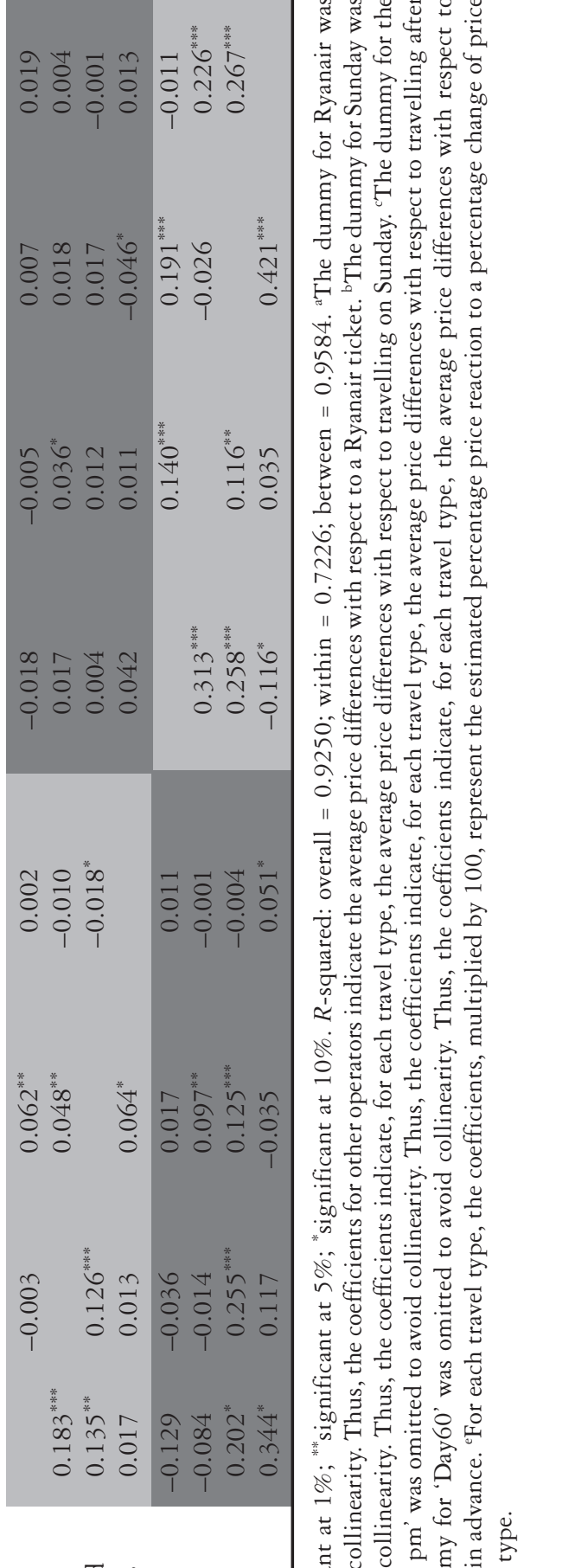

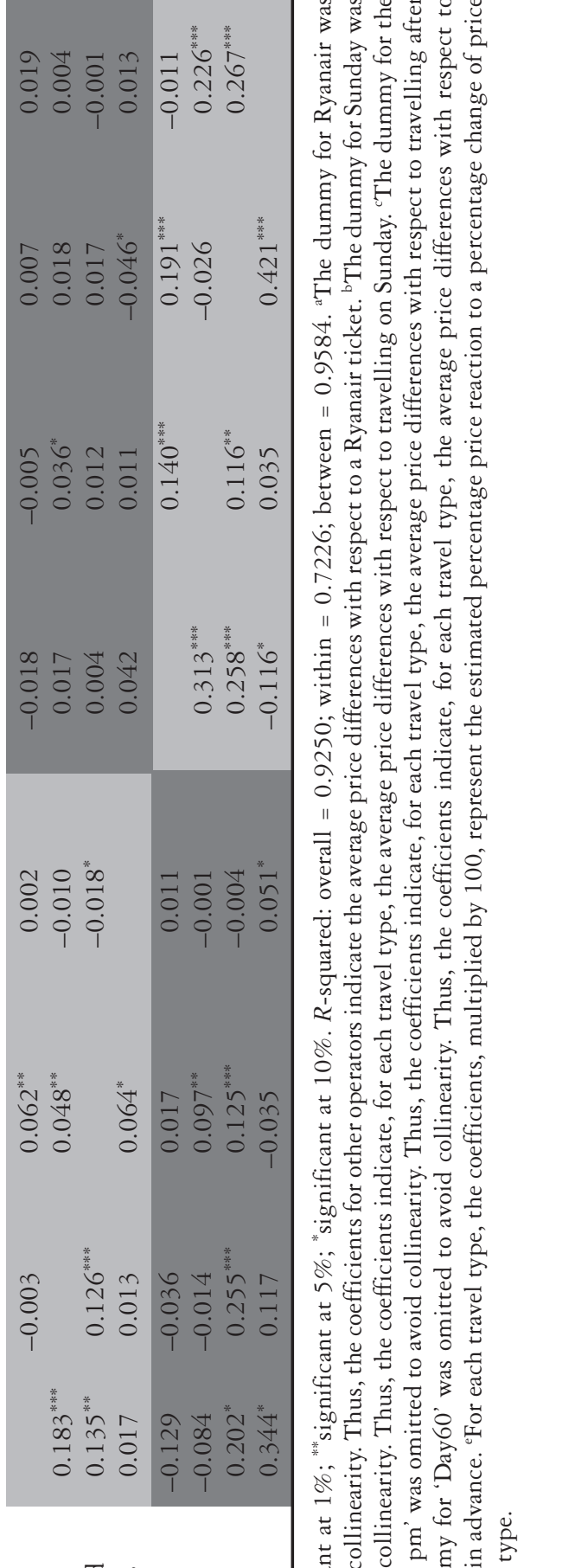

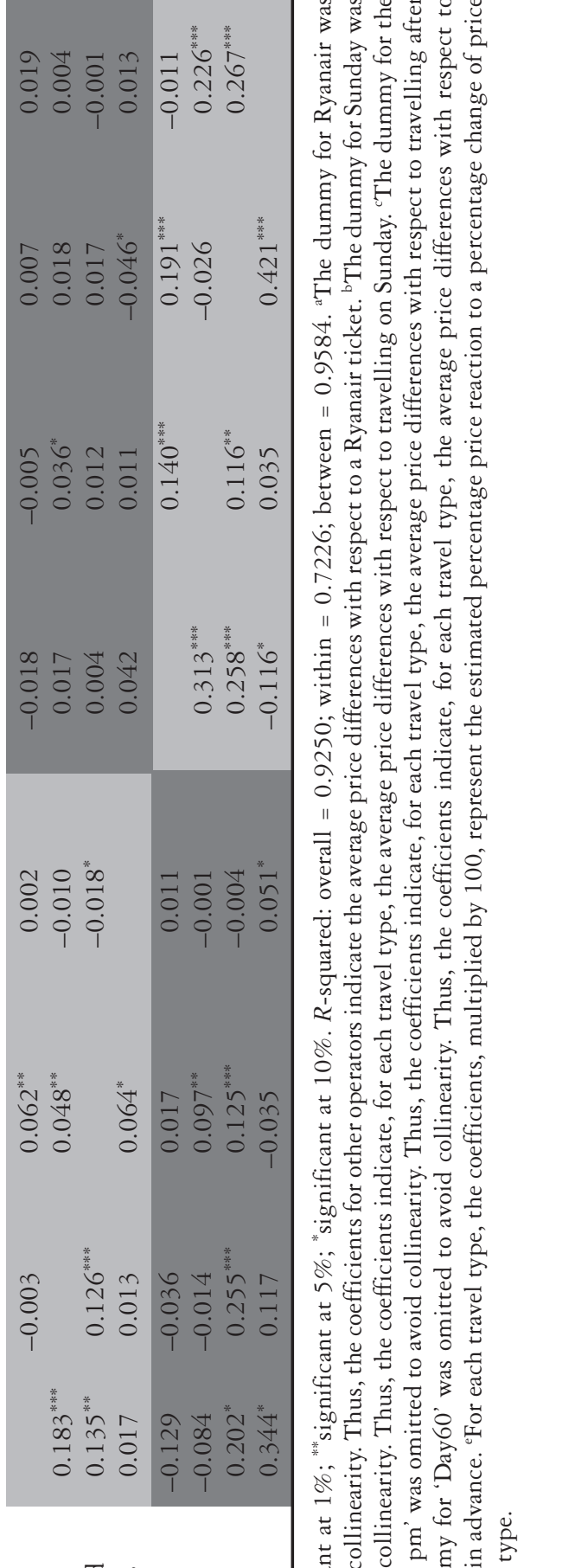

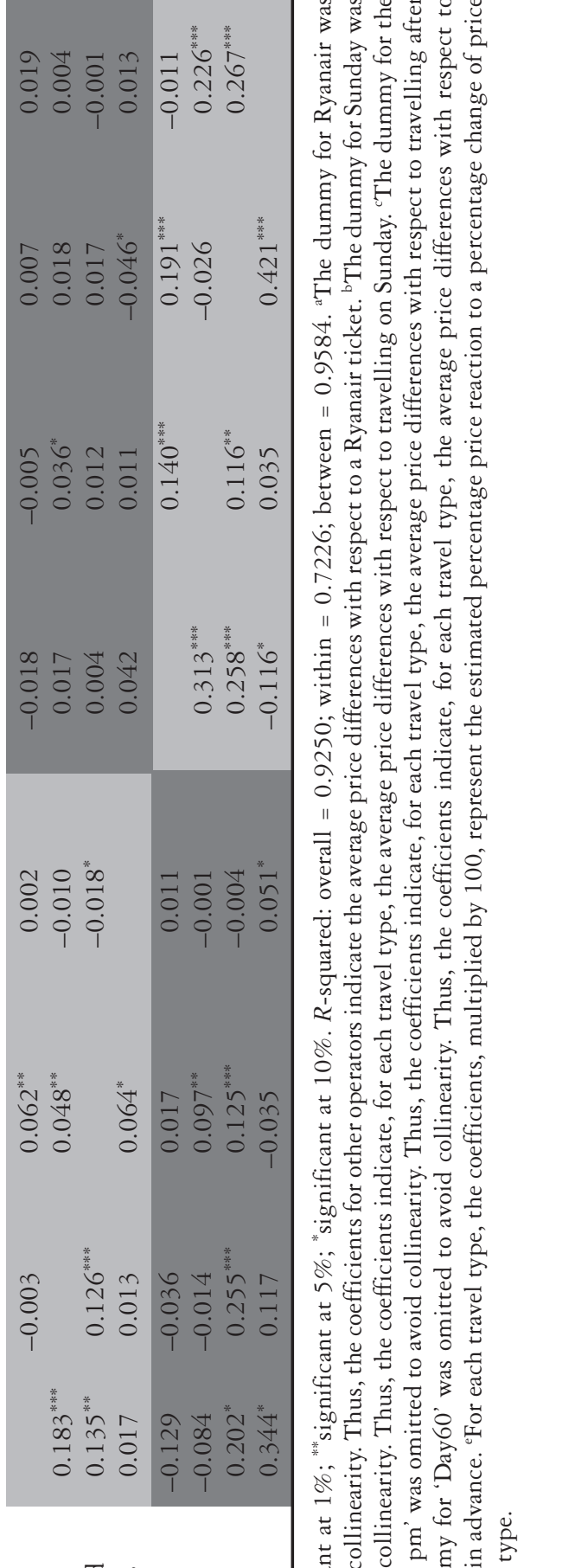

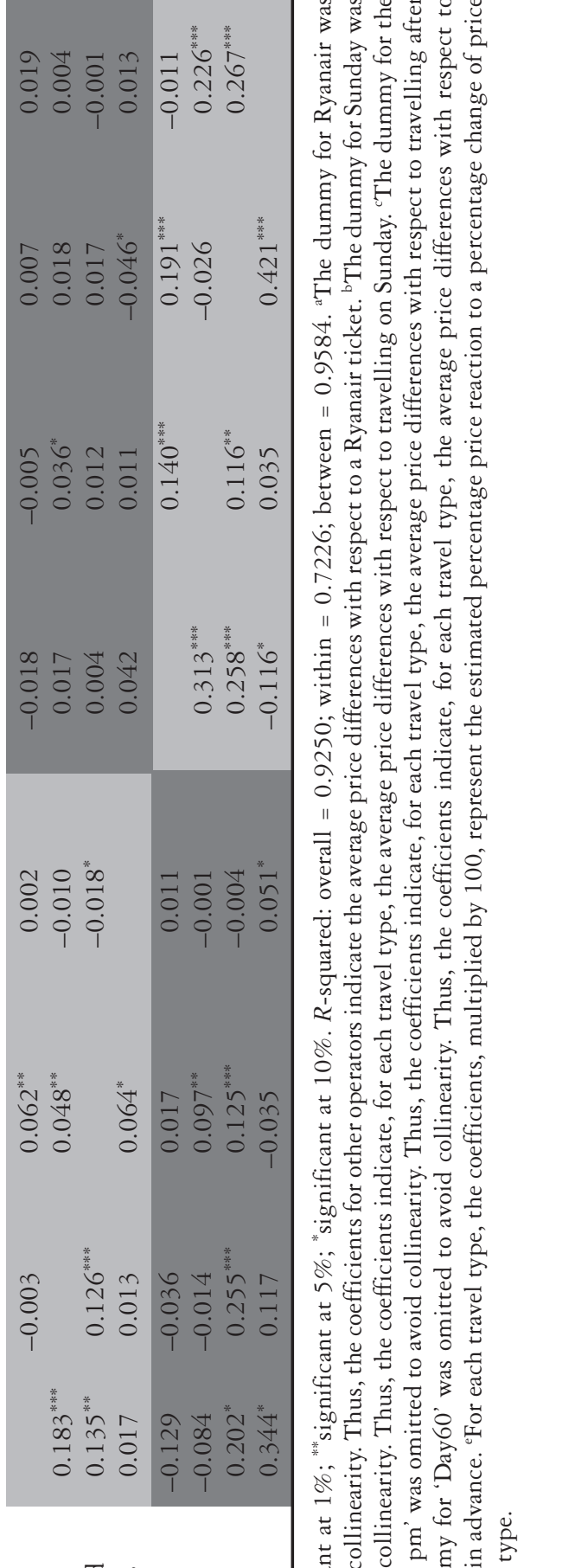

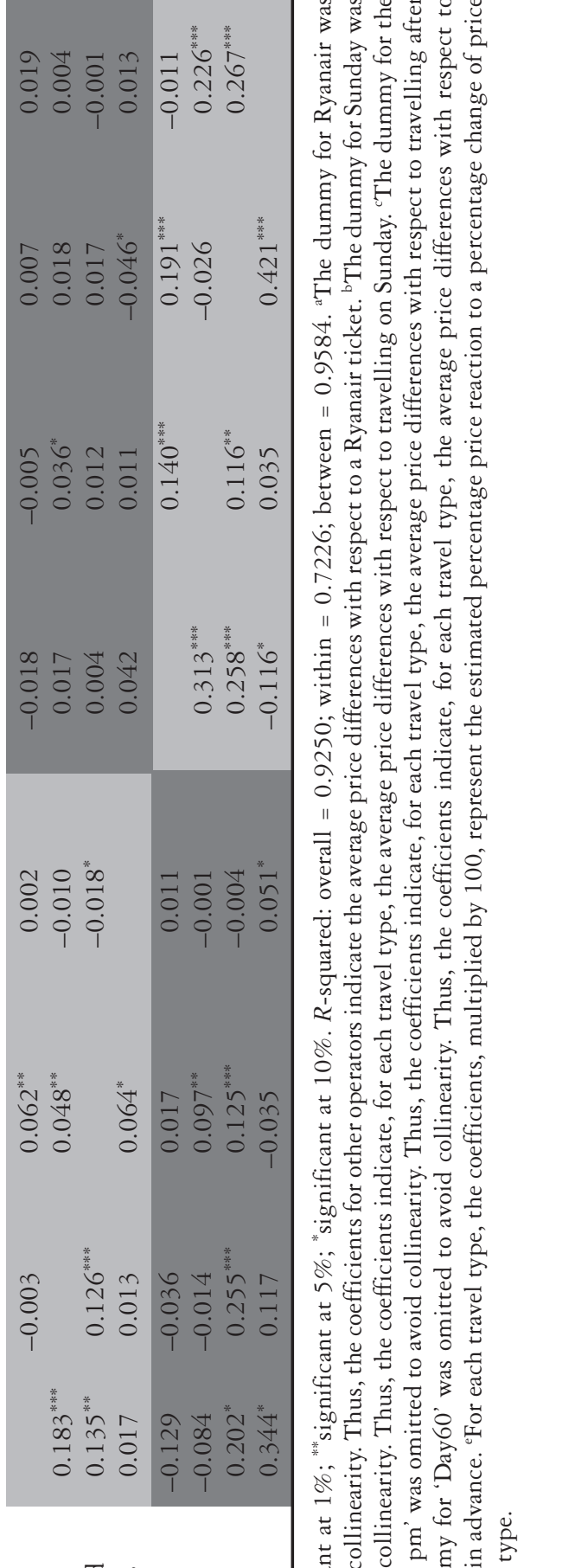

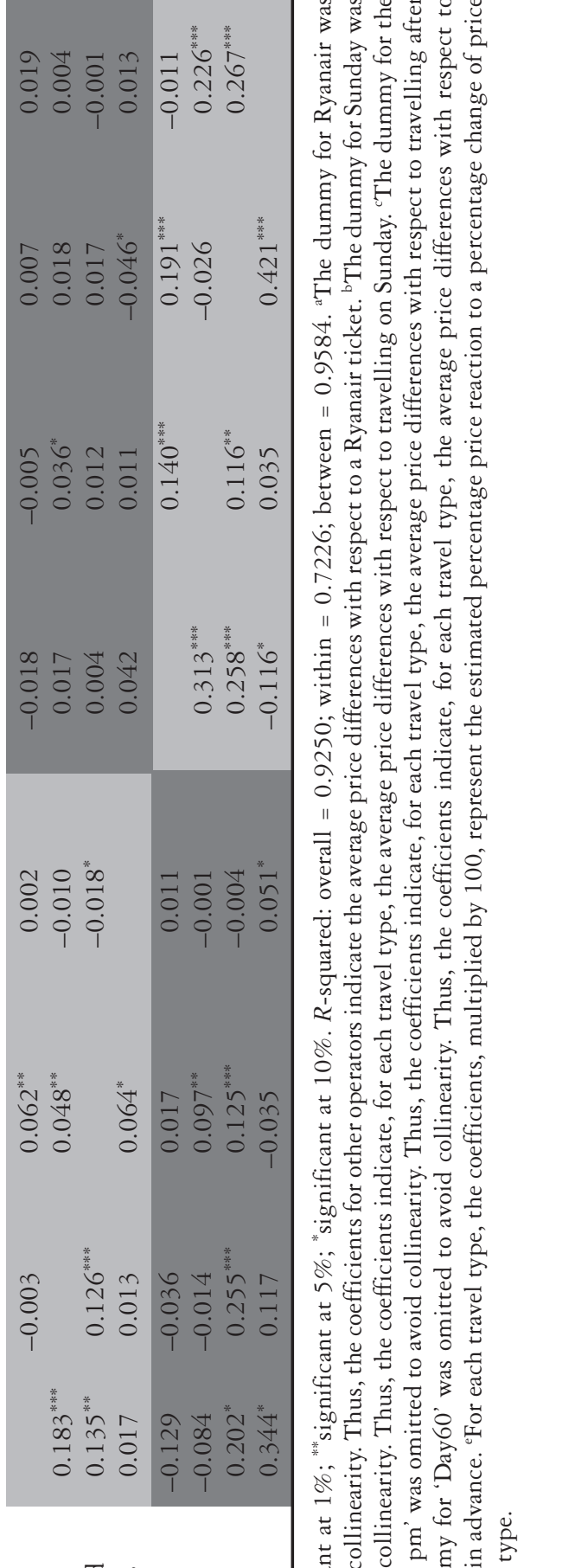

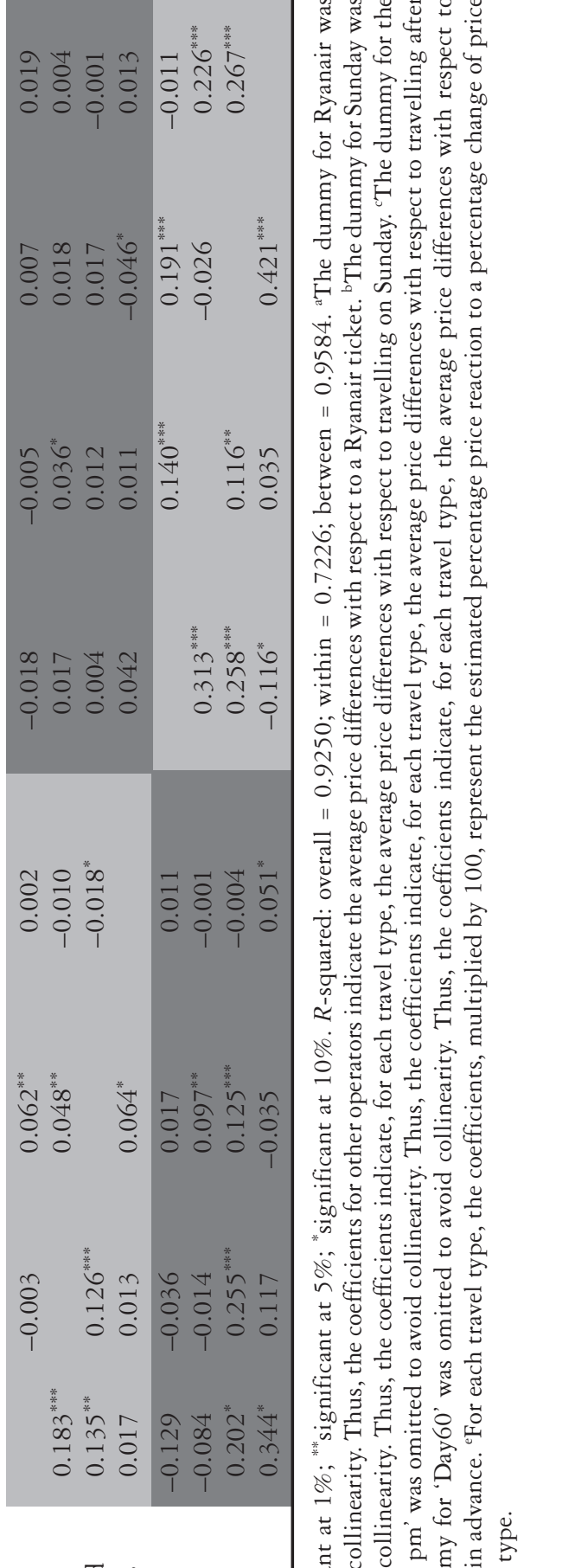

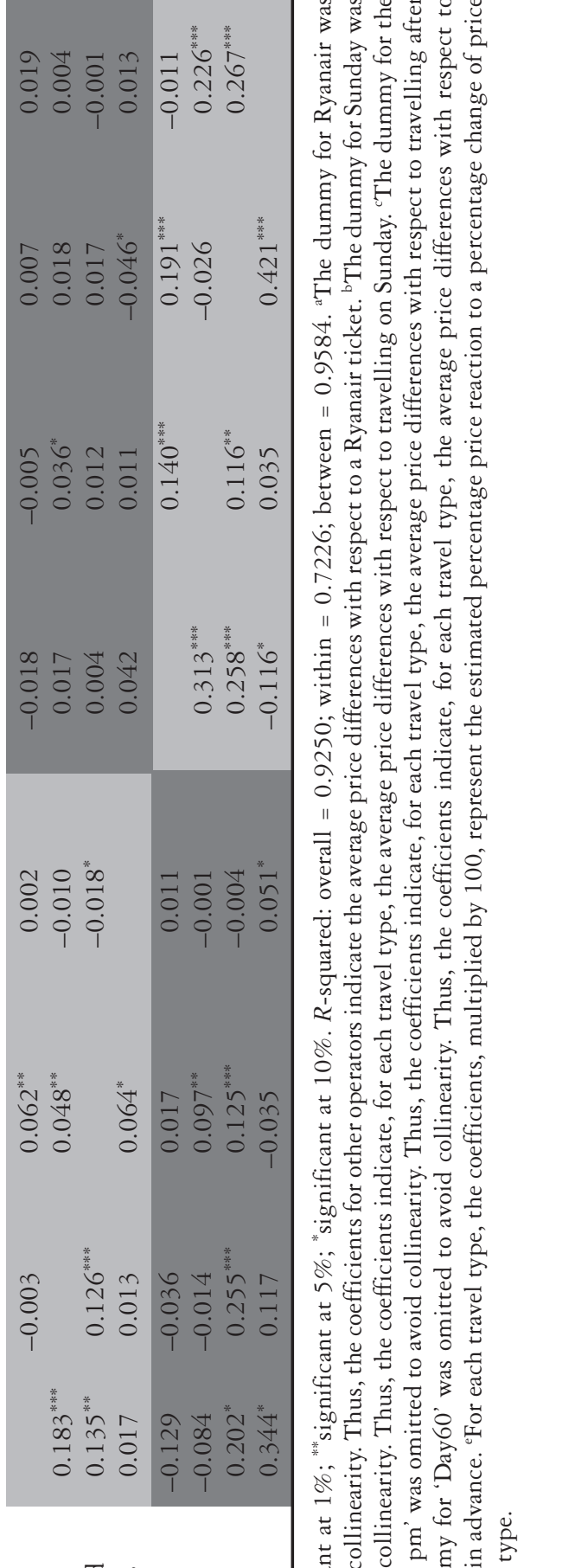

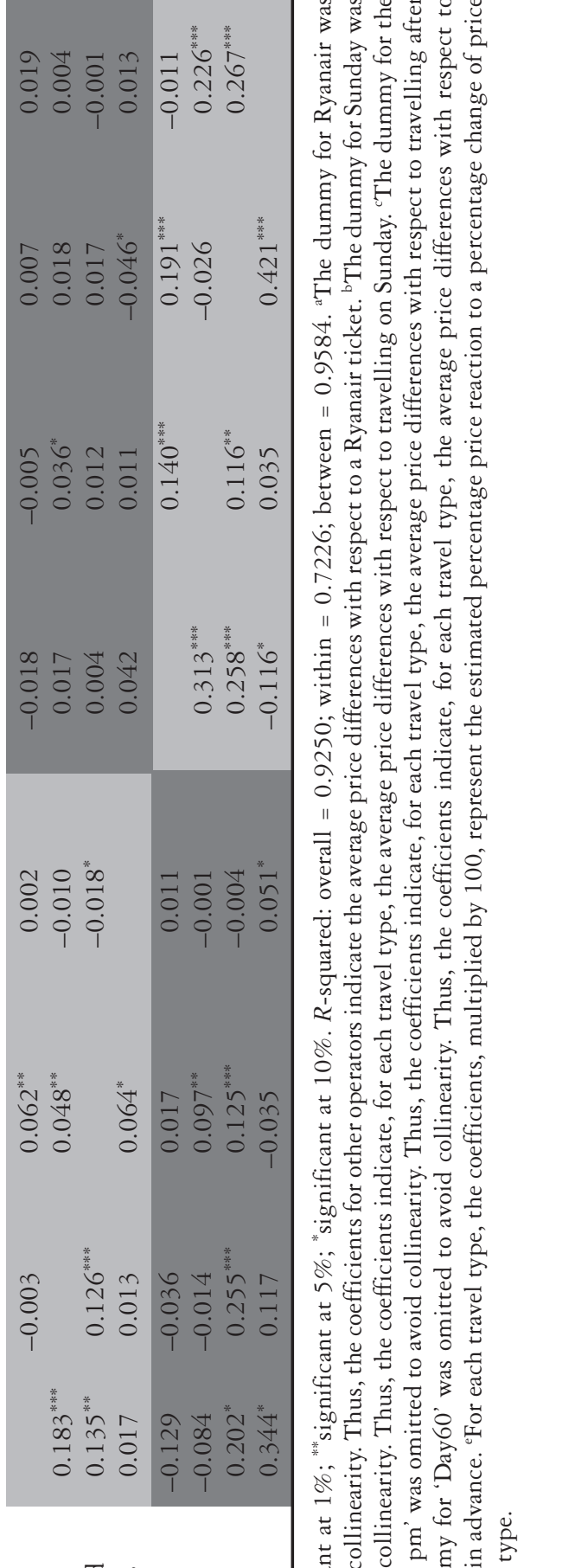

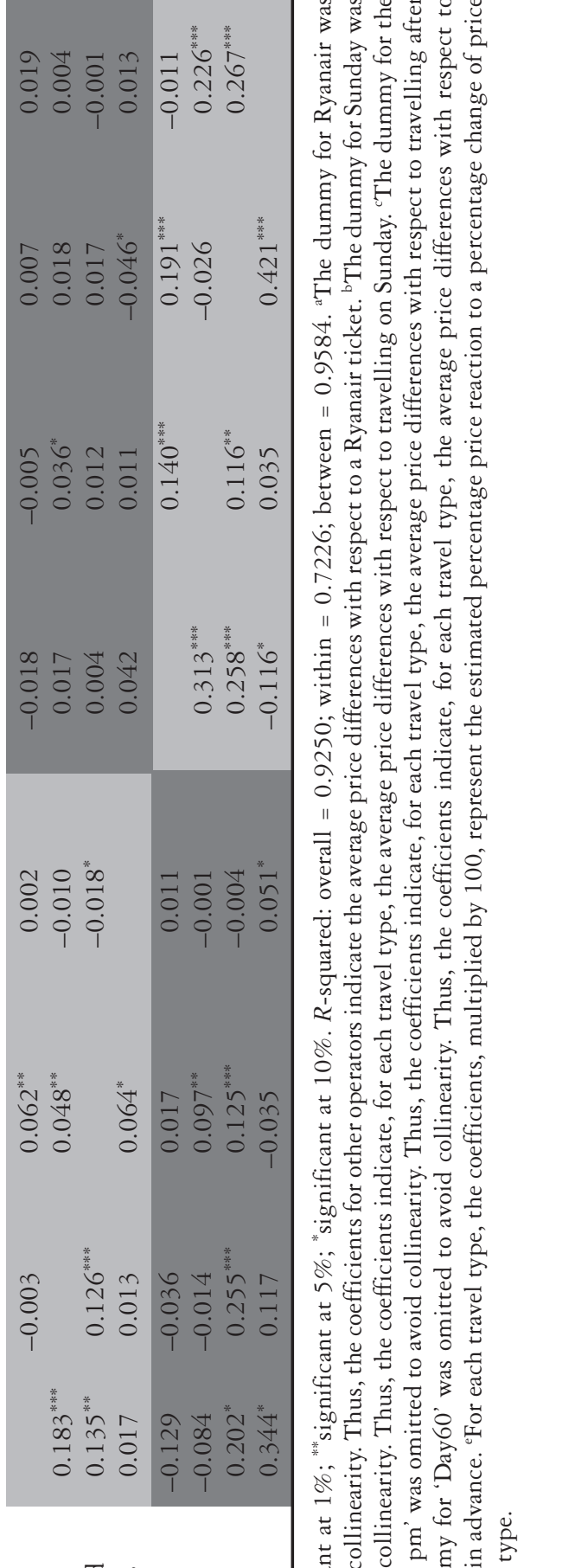

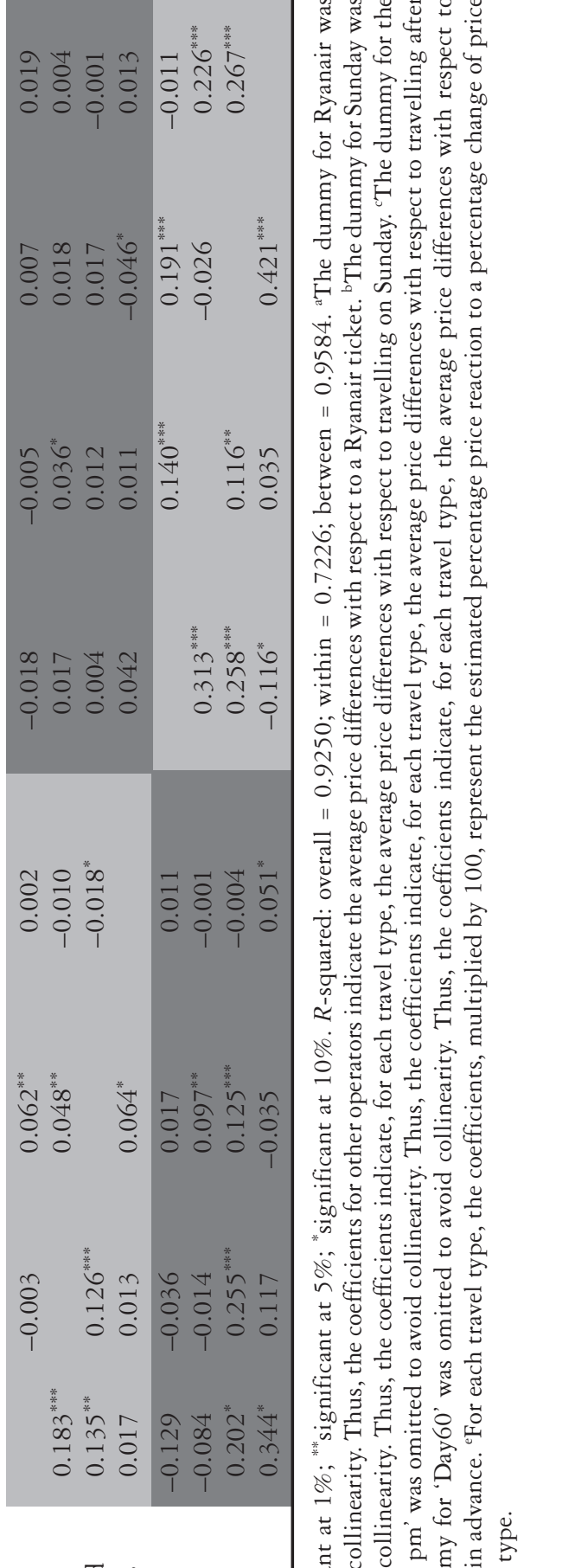

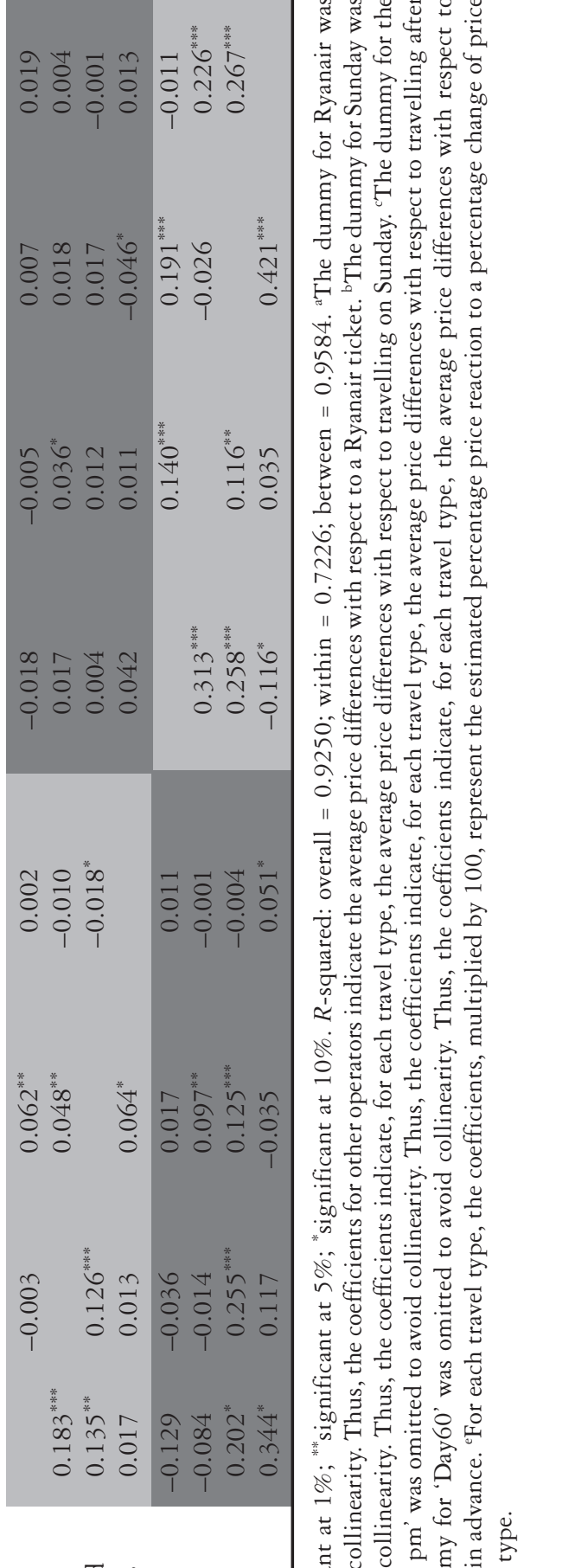

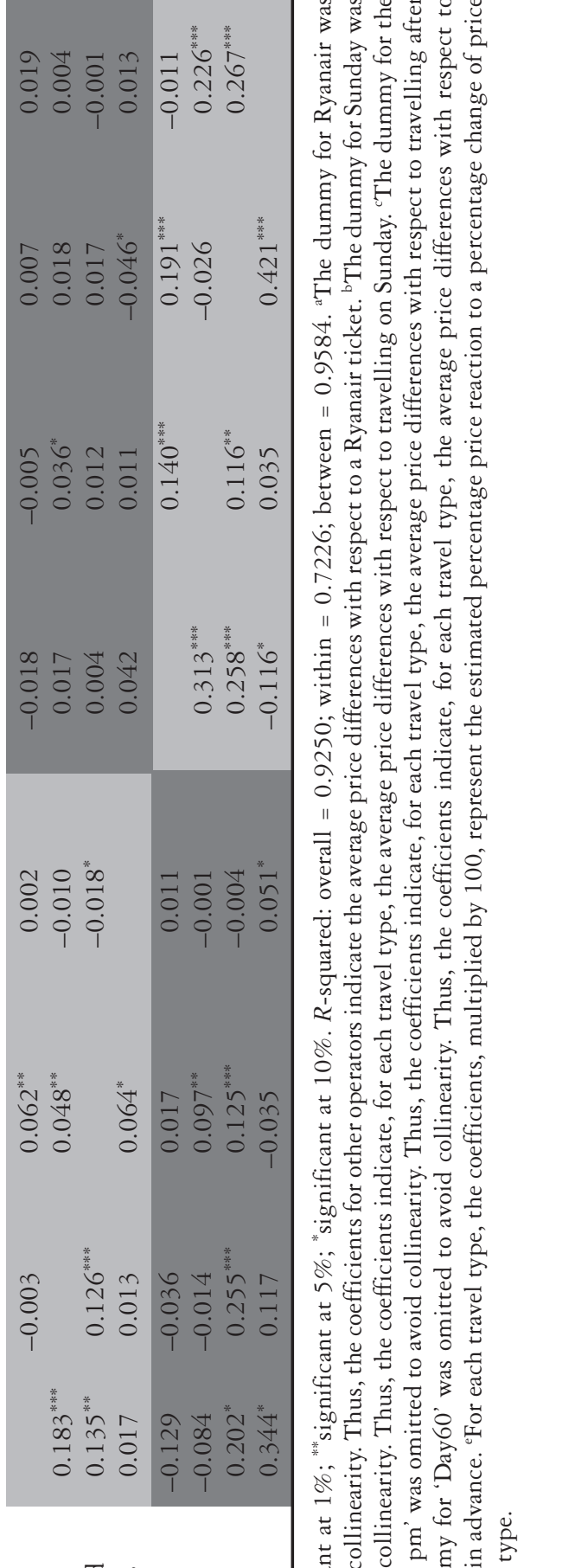

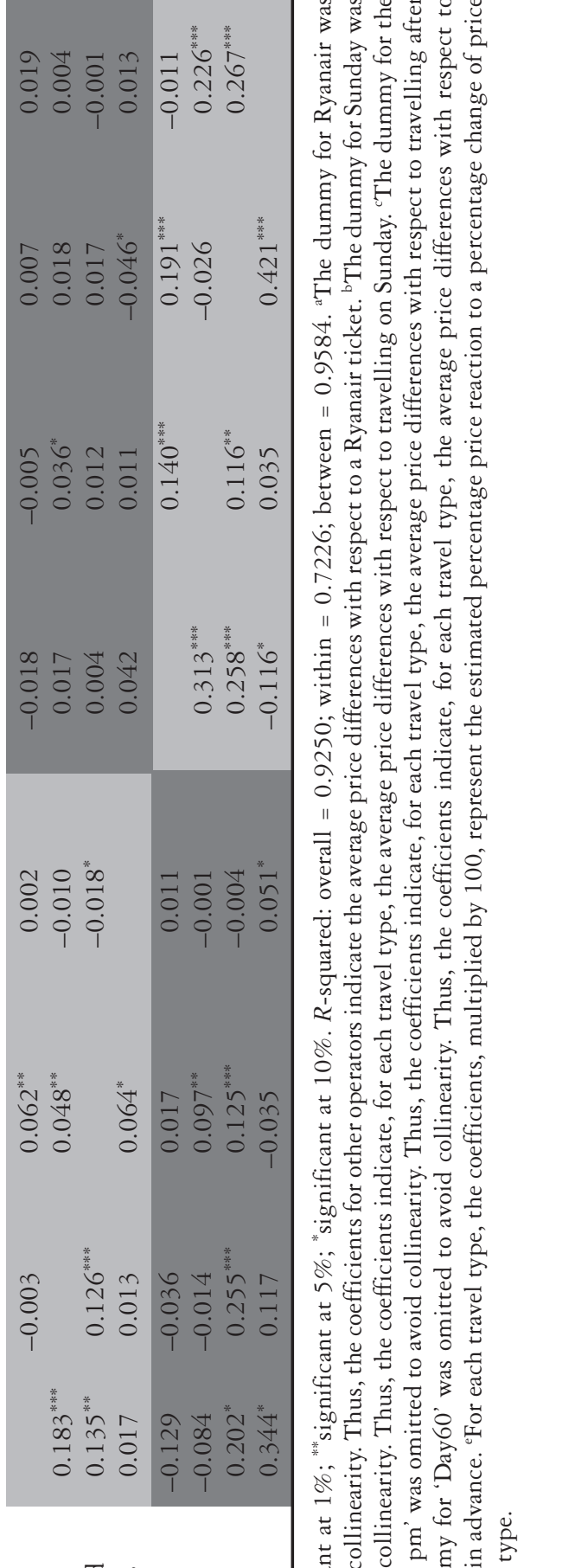

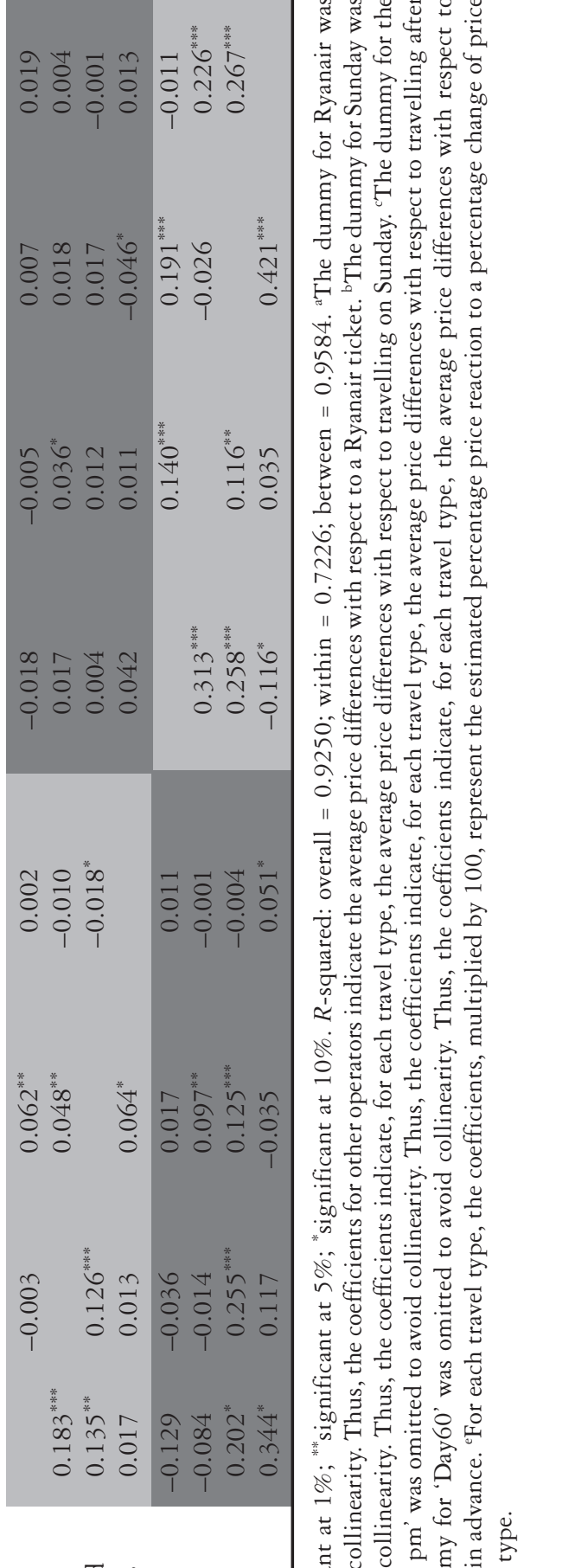

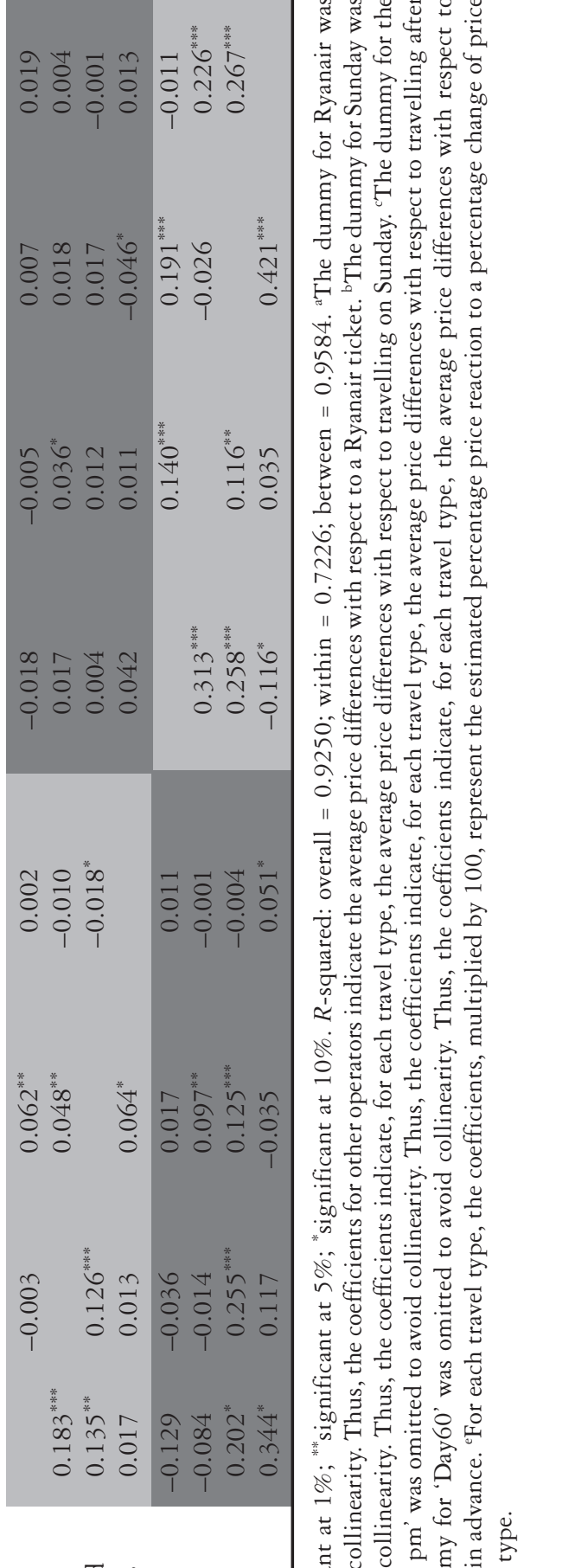

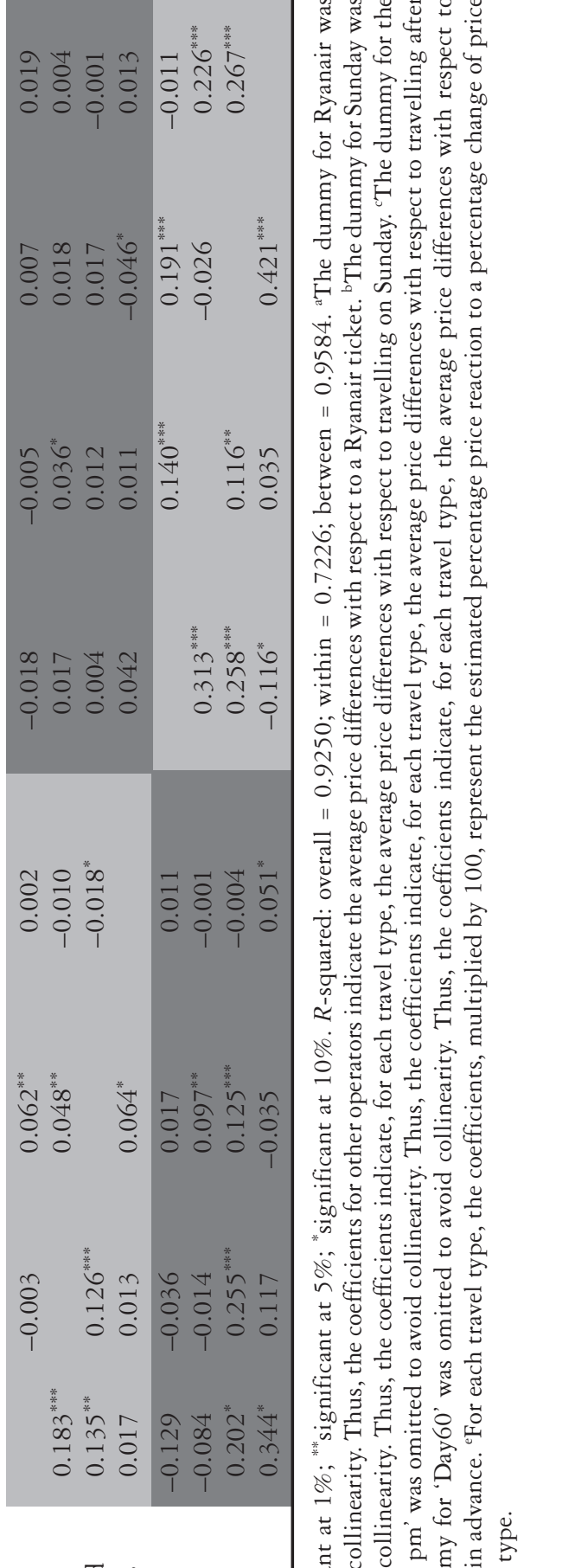

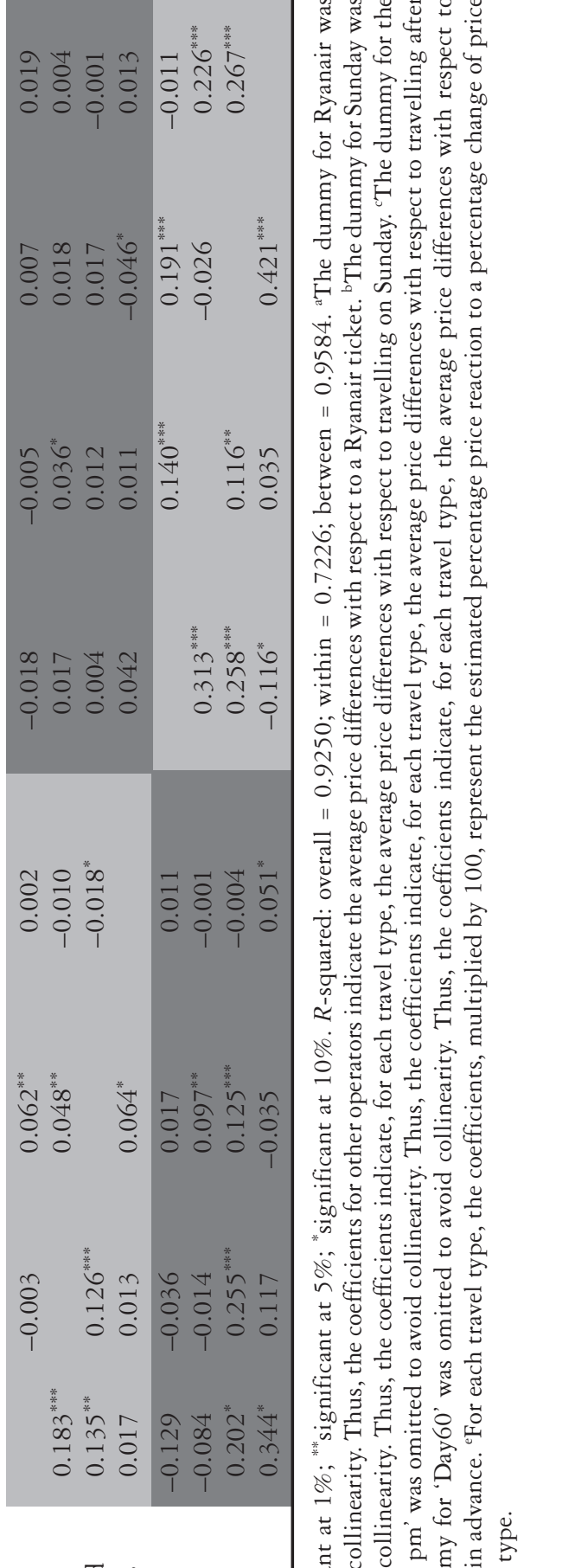

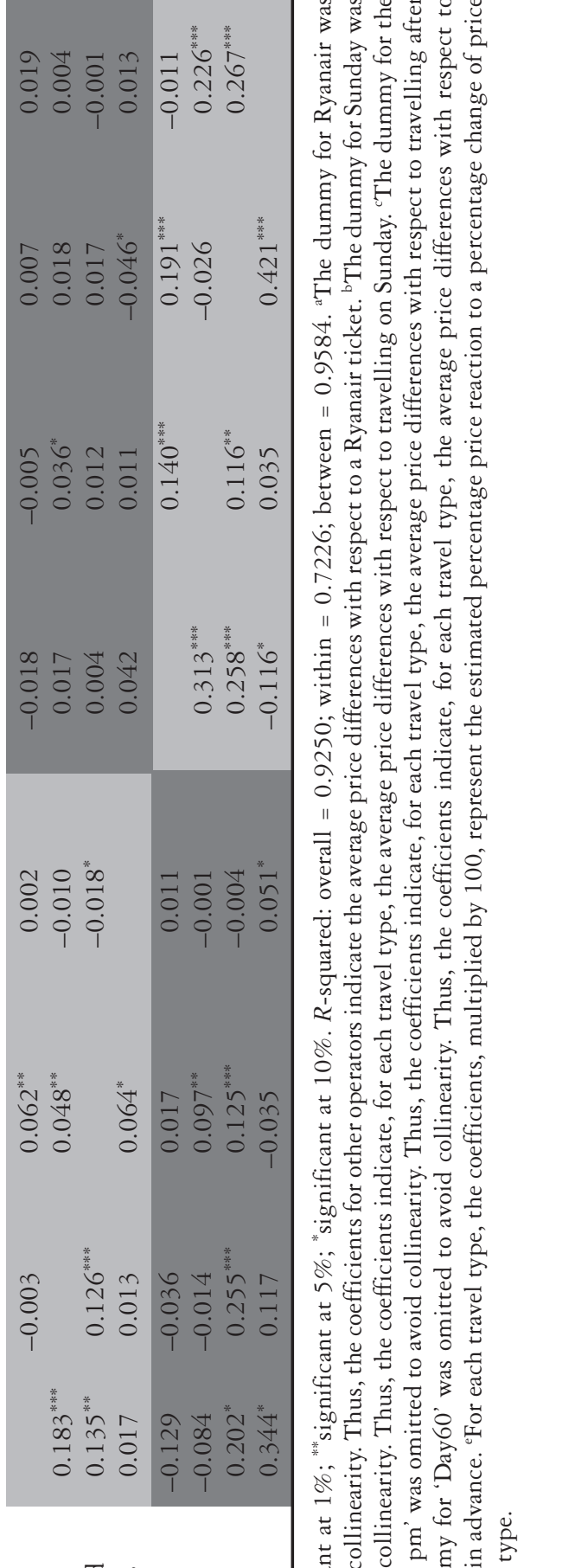

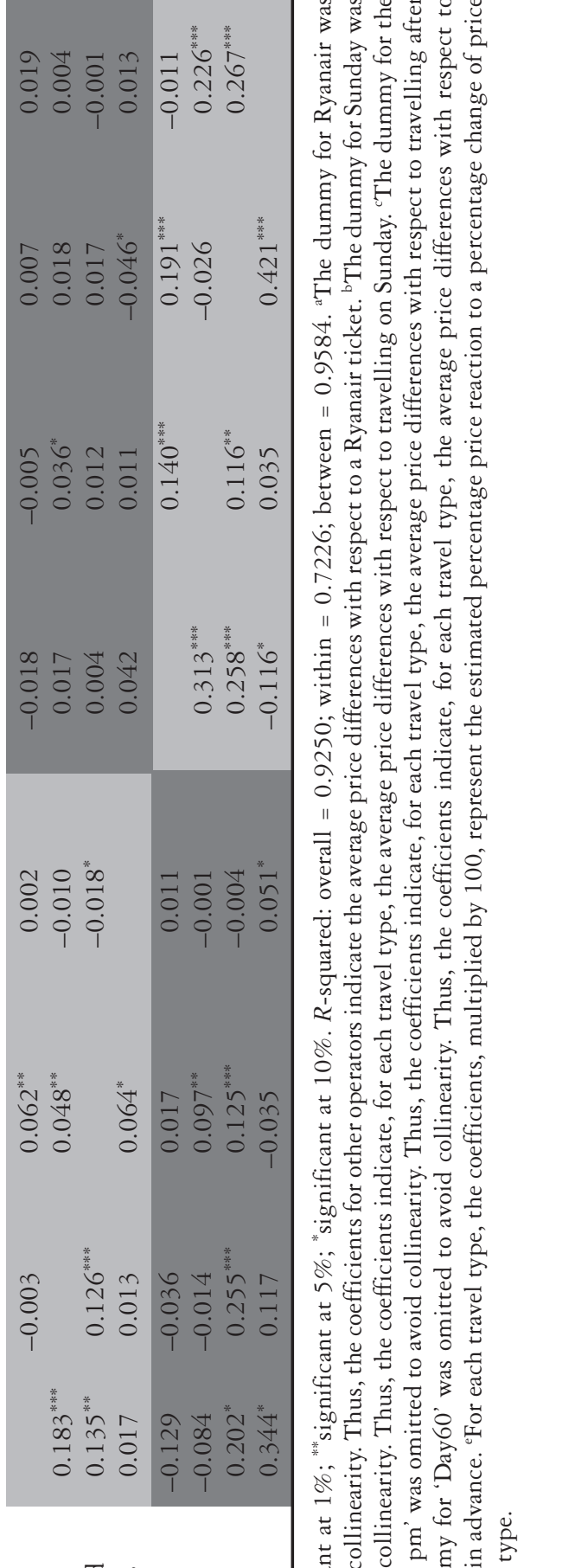

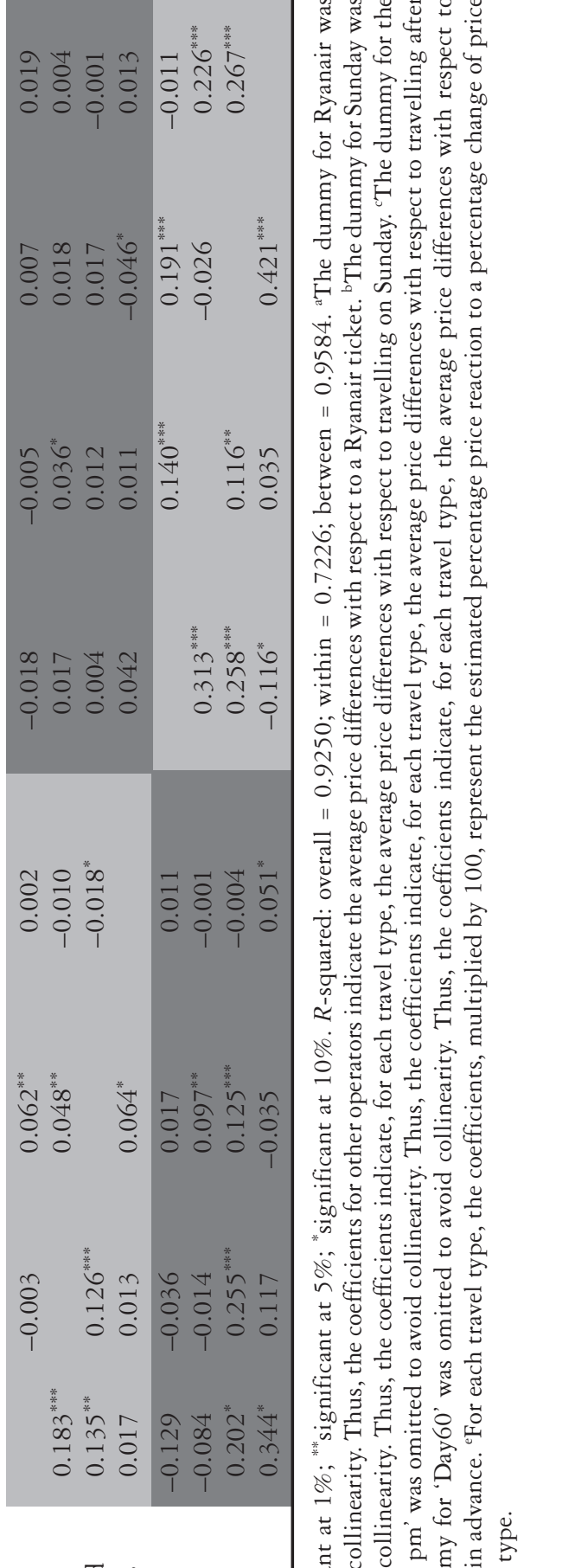

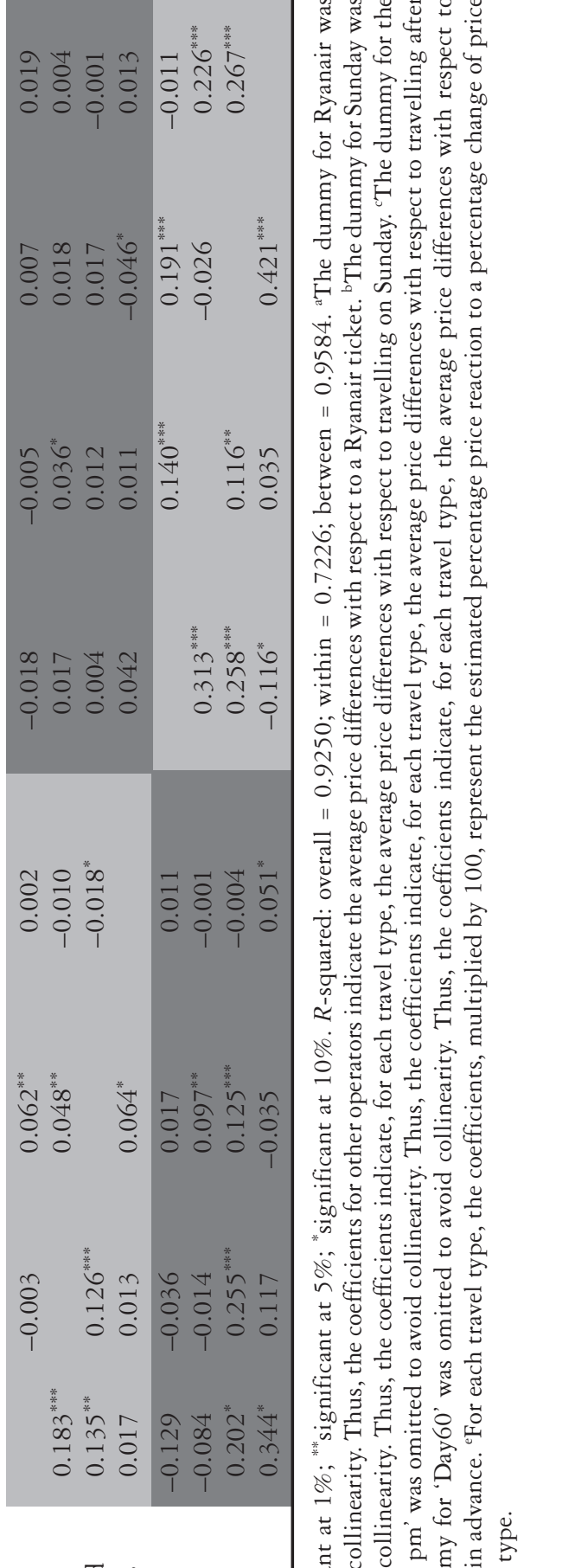

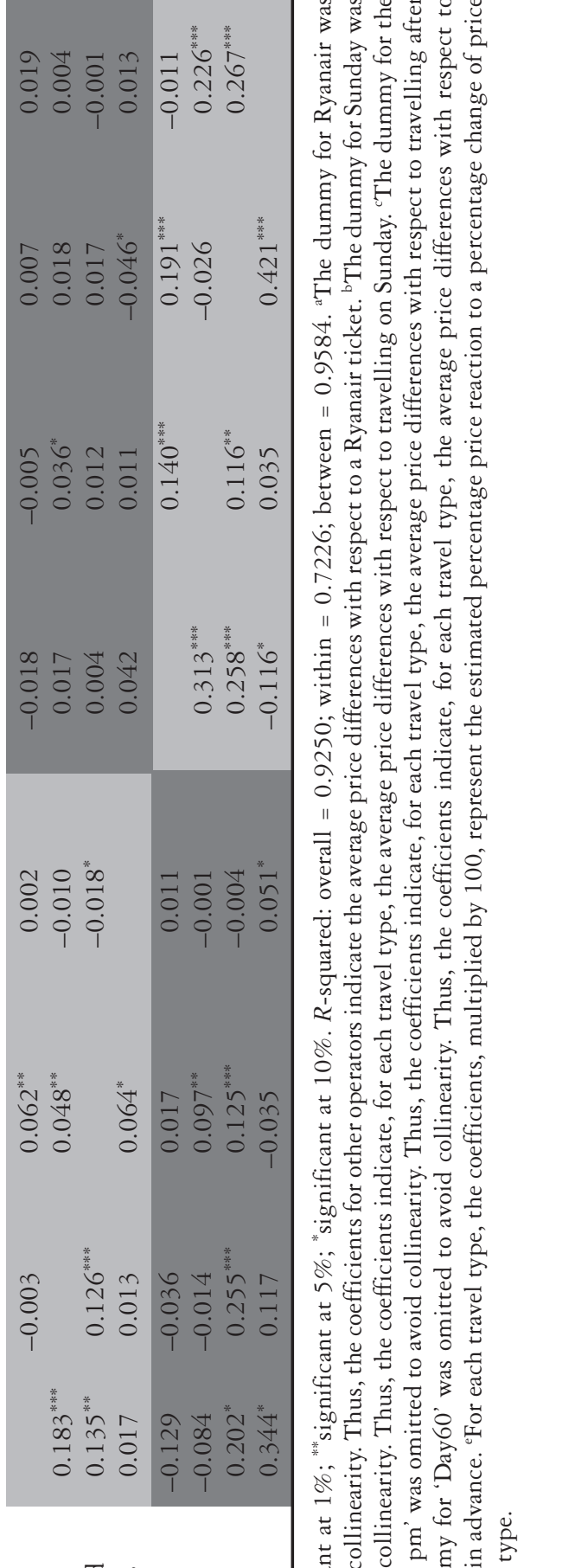

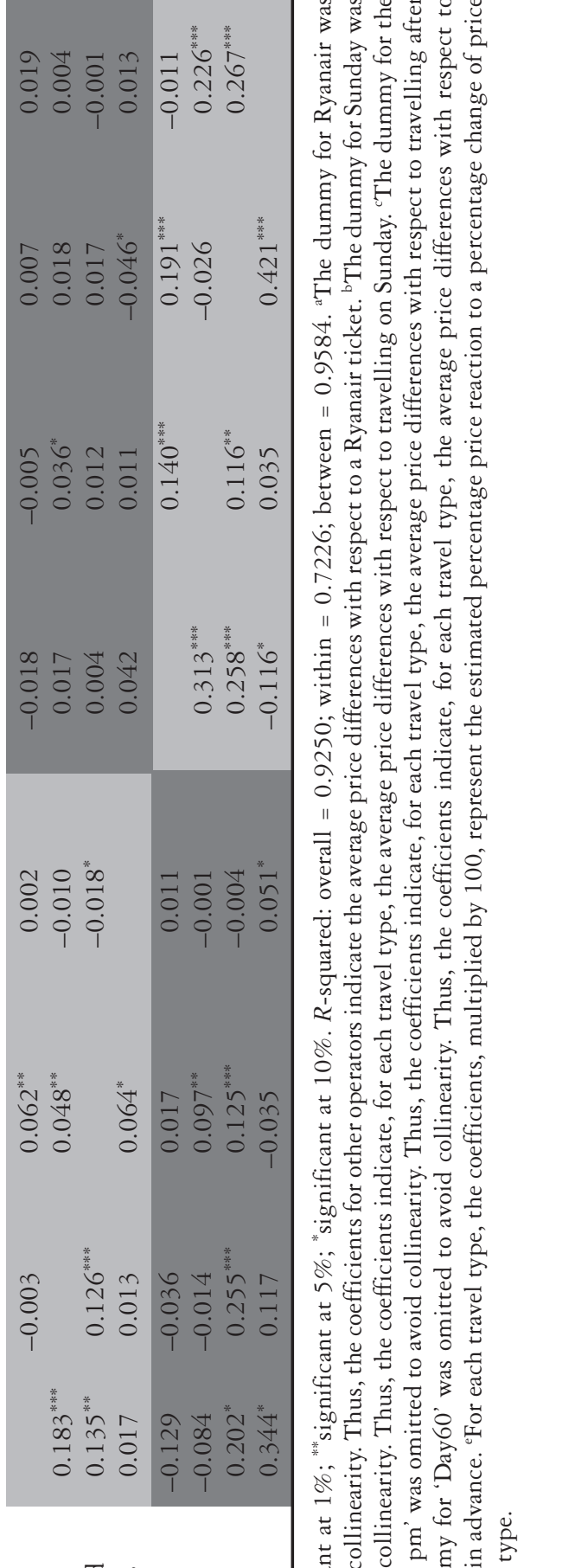

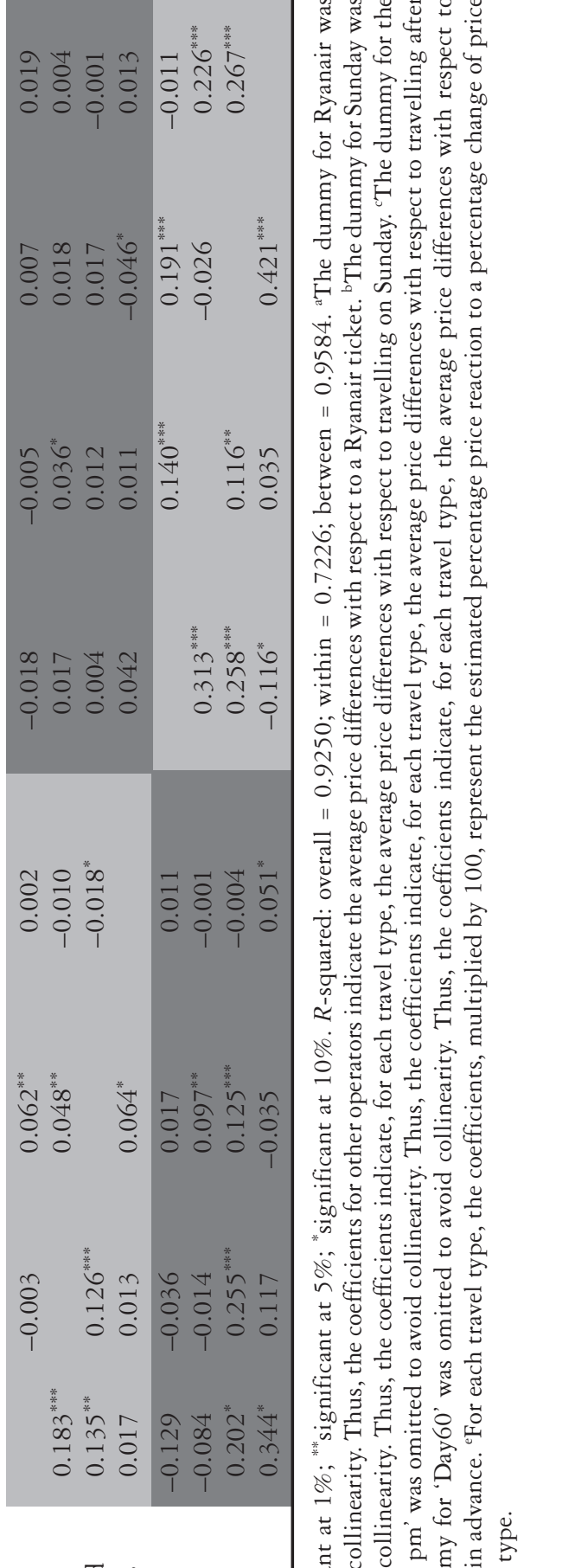

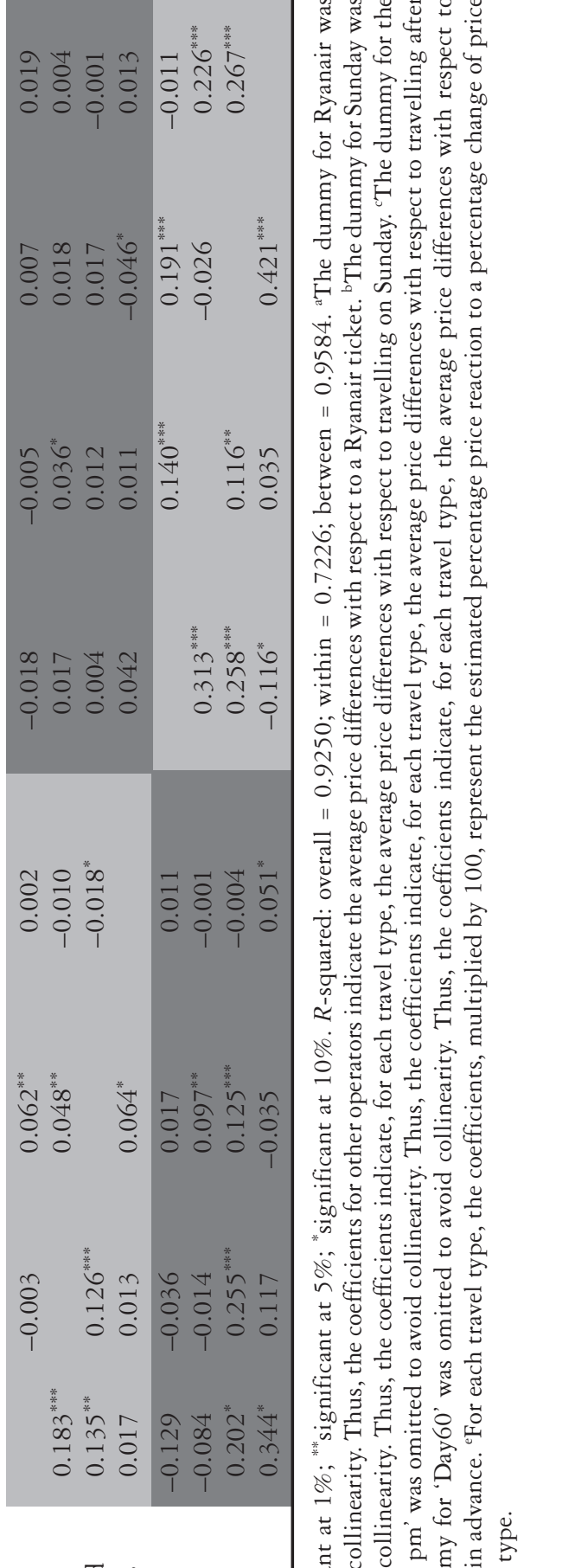

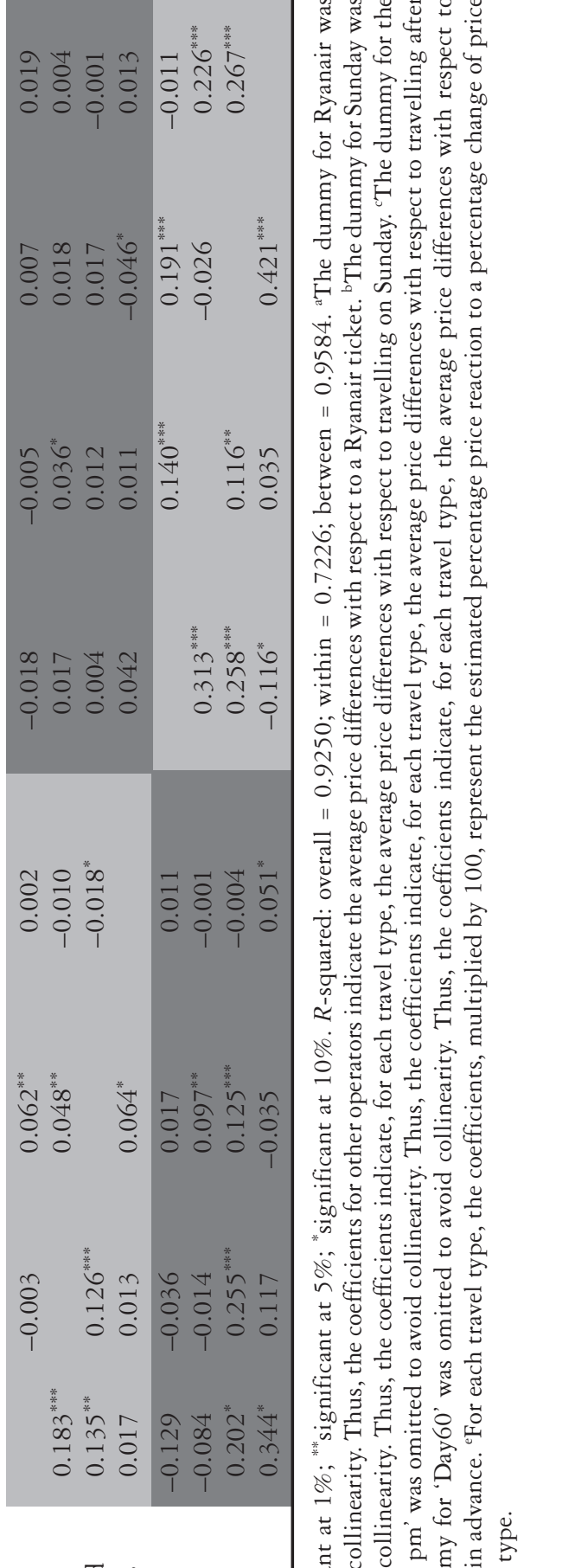

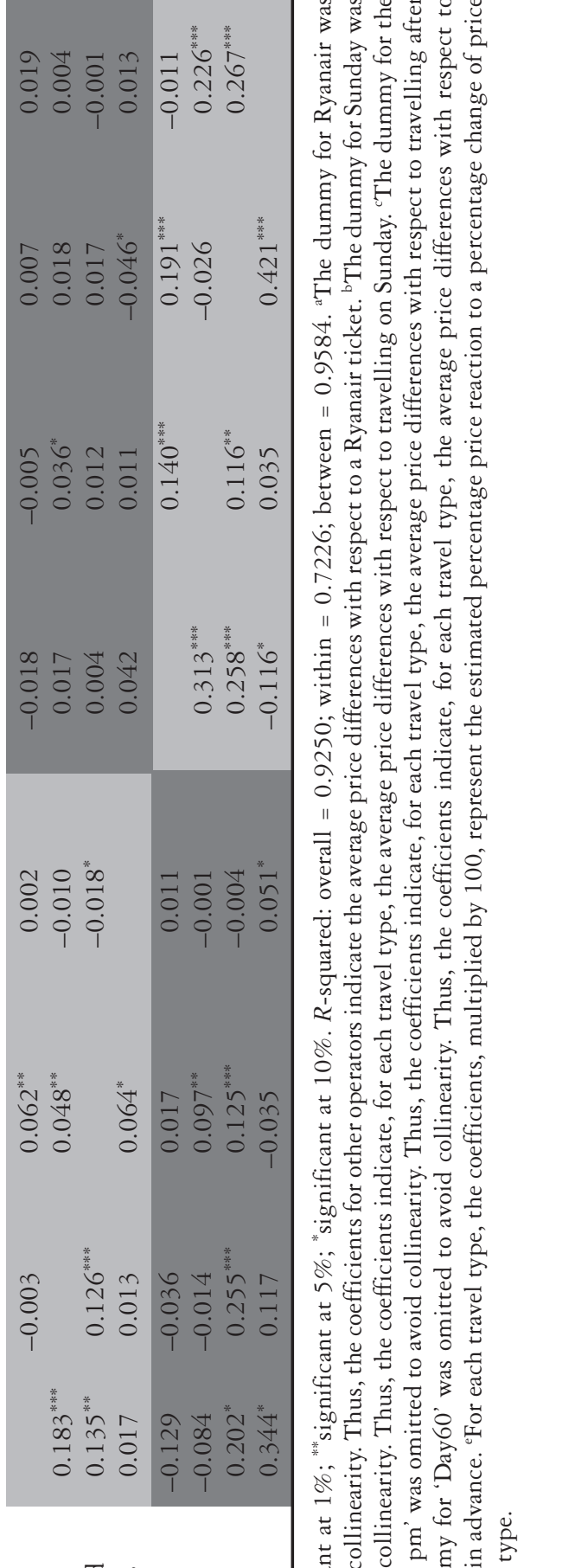

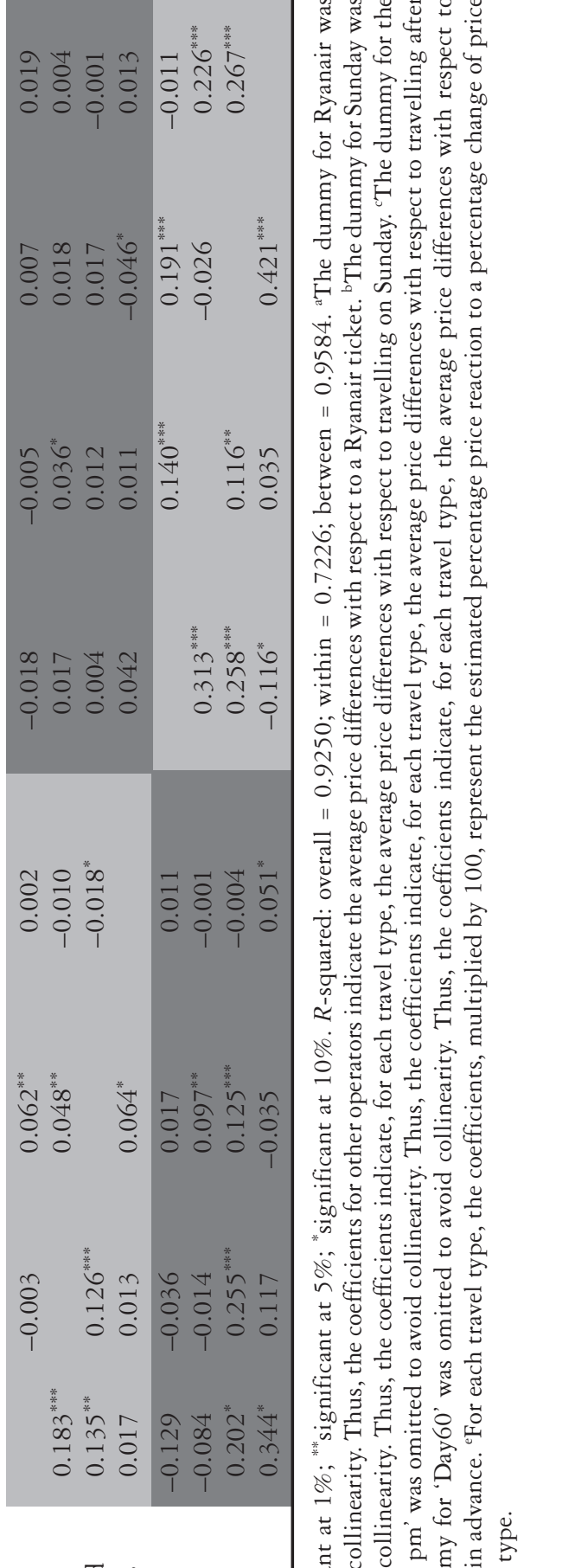

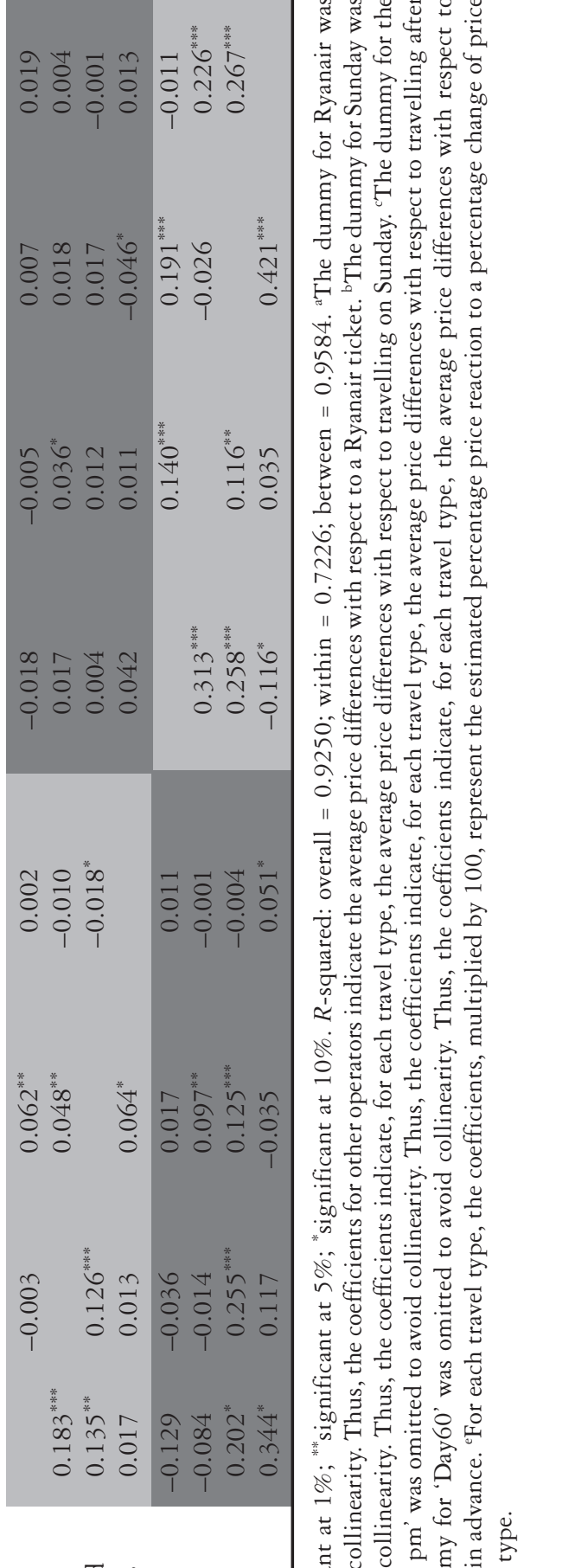

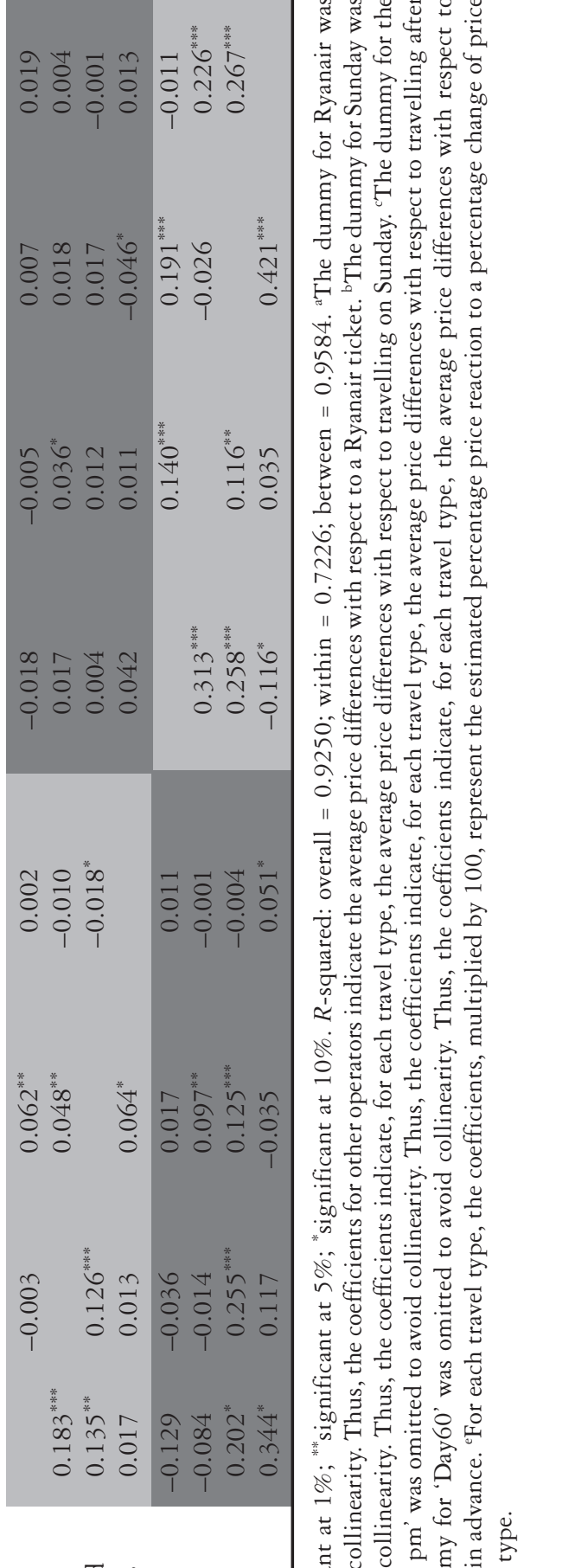

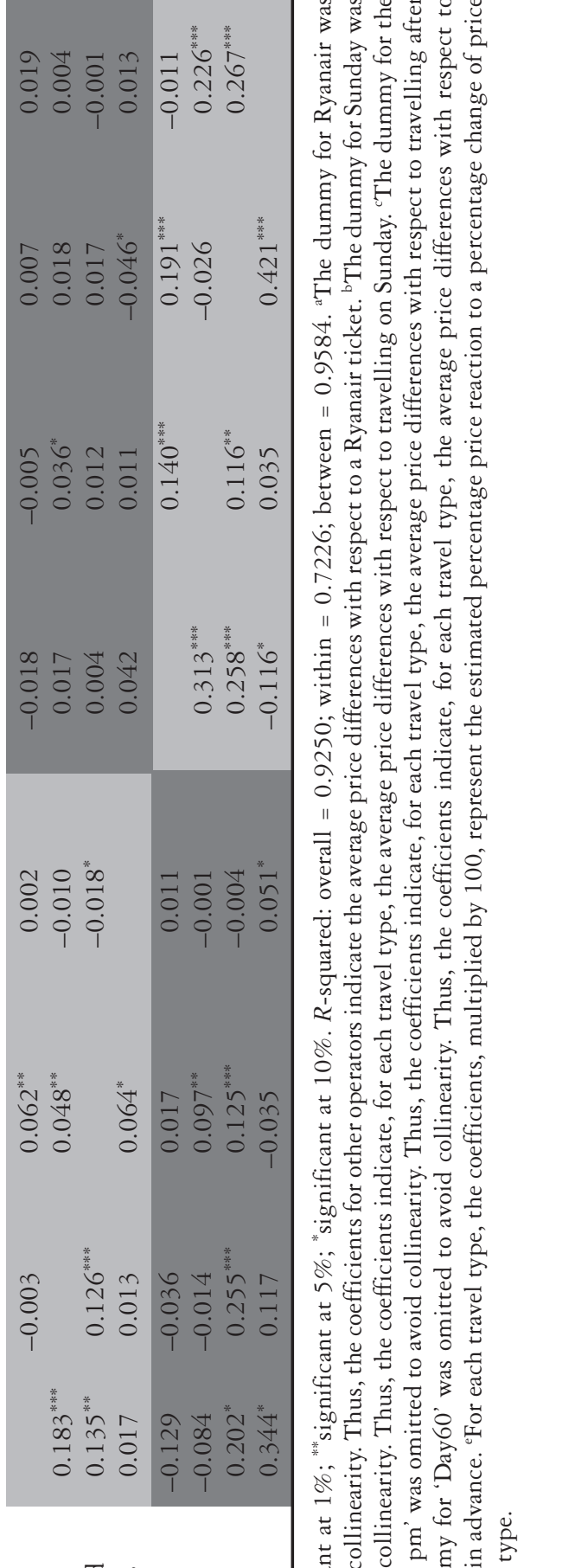

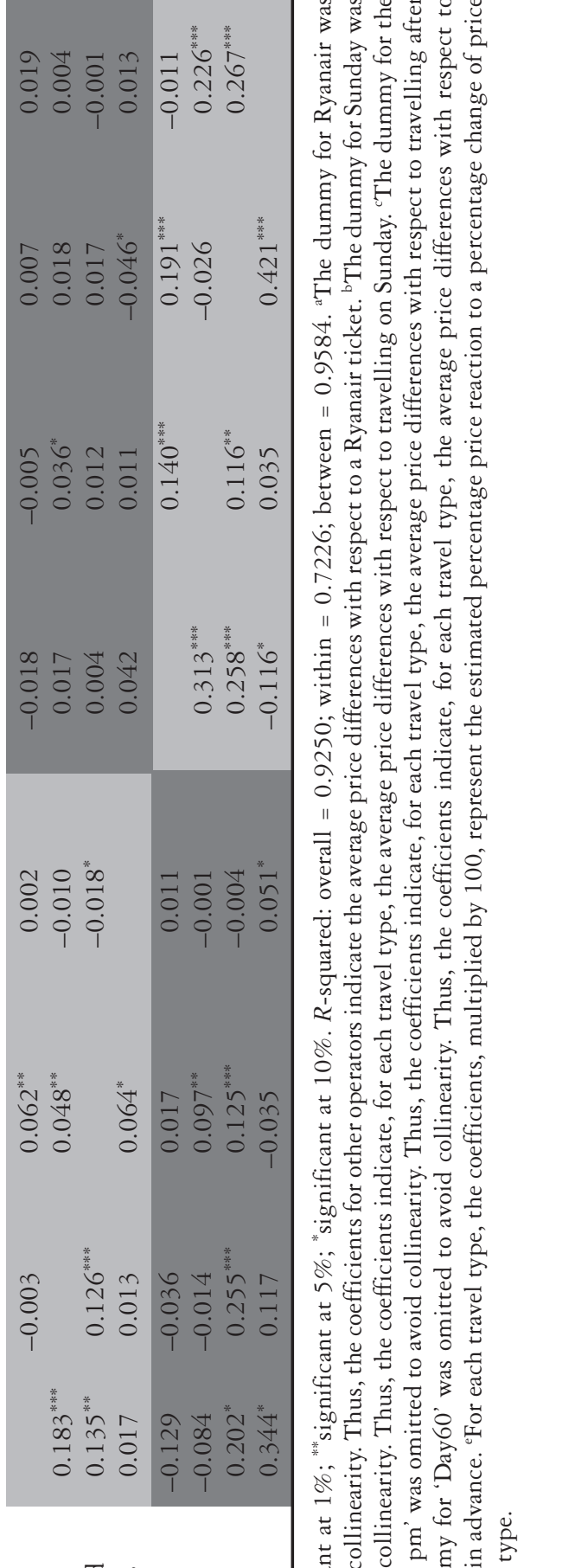

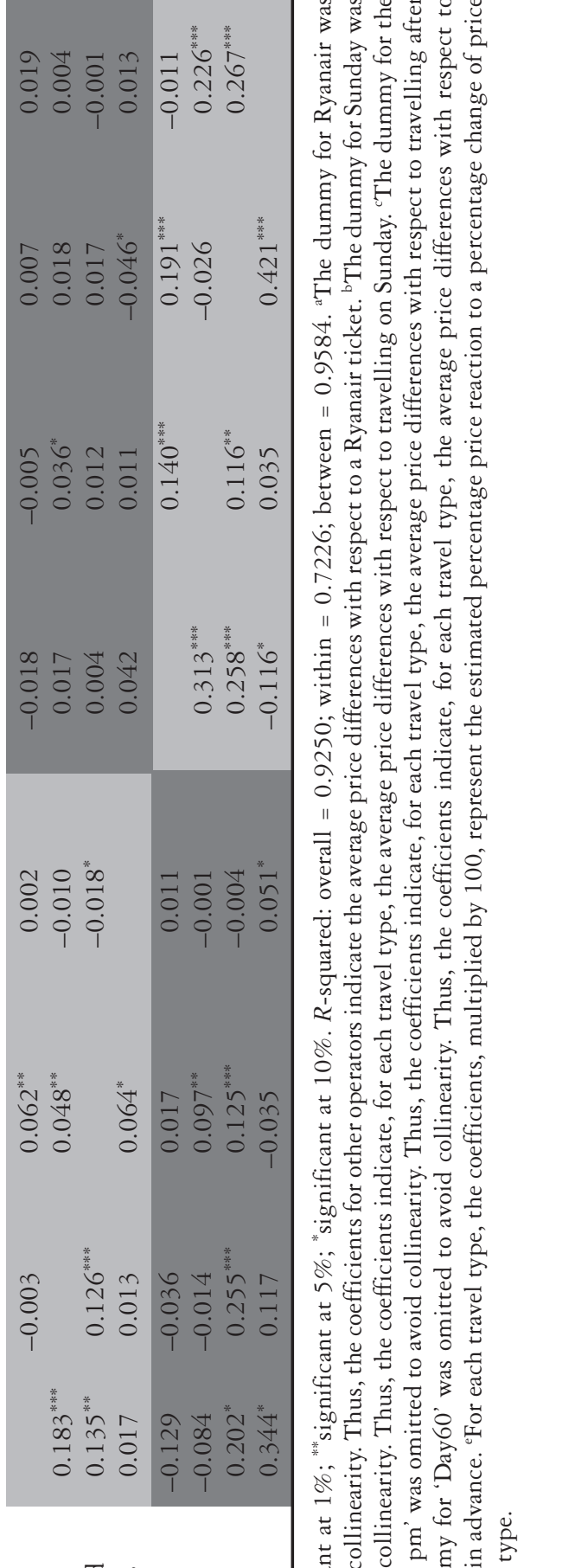

$\sum_{1}^{0}$

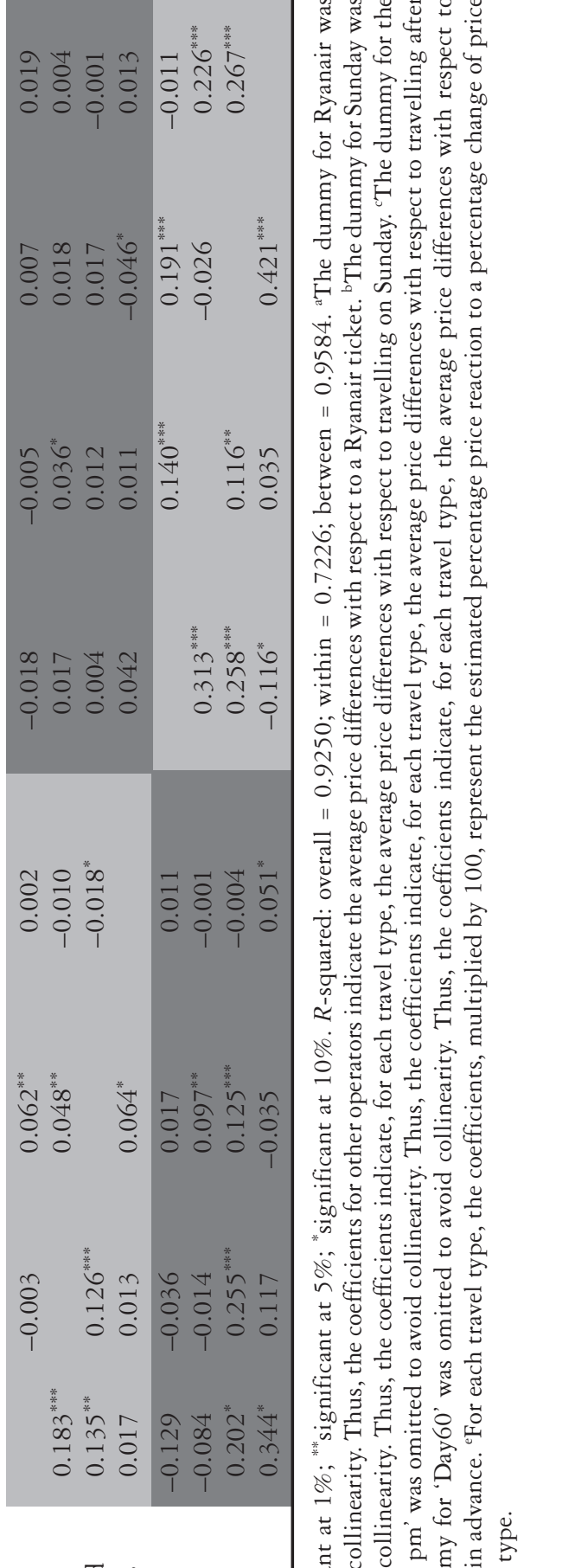

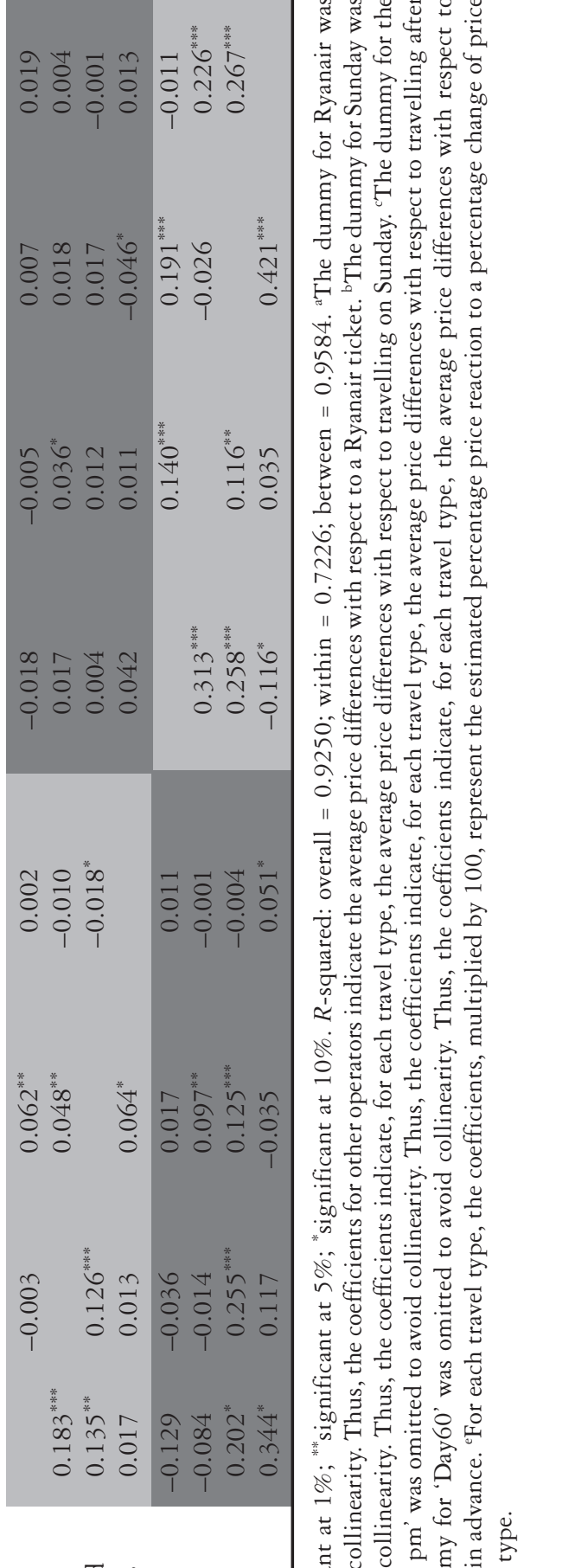

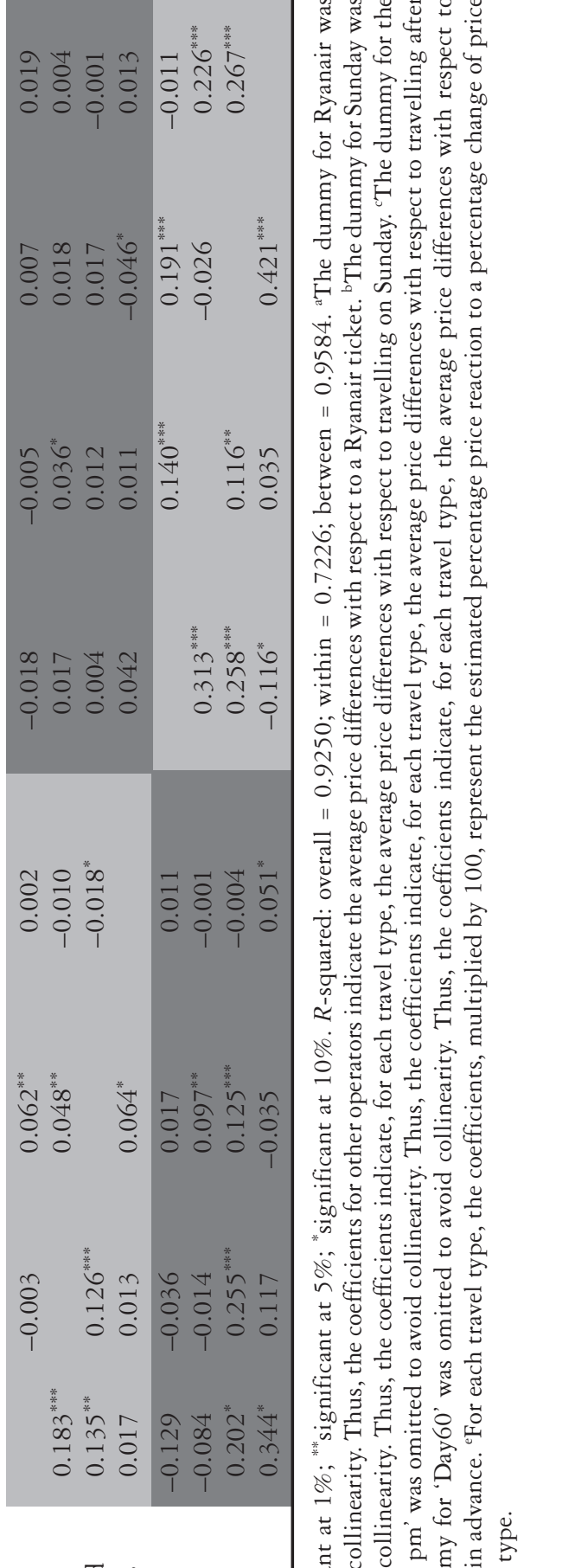
践

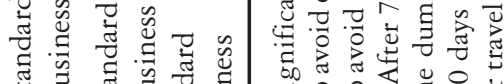

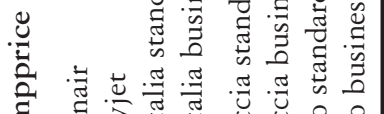

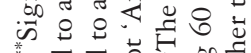

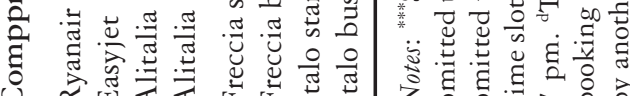


control variables concerning the average difference between travel modes and the impact of weekday and peak hours can usually be interpreted intuitively. Not surprisingly, Ryanair is the cheapest option while, on average, Alitalia is the most expensive carrier (especially in the case of business class), followed by Frecciarossa business. As to day of the week, in almost all cases fares tend to be lower on mid-week days, with a more accentuated discount associated with the less expensive travel modes (in particular, Ryanair, Italo standard and Frecciarossa standard). This might be caused by less expensive travel modes being the preferred option for leisure customers, whose demand peak is at the weekend. However, this discounting behaviour does not seem to be significant in the case of the most expensive business tariffs (Alitalia business and Frecciarossa business), with the extreme case of Alitalia which places the most convenient price promotions at the weekend. This is coherent with the target segment of Alitalia, mainly composed of business customers travelling during working days. As to the within-day price variations, flights in the morning and evening slots tend to be more expensive. In the case of trains the highest fares can be found in late afternoon ( $4 \mathrm{pm}-7 \mathrm{pm})$, with lower prices registered after $7 \mathrm{pm}$. A possible explanation for such a finding is that peak hours are slightly different for flights and trains, as peak hours for trains are anticipated (trains departing directly from the city centre).

Table 2 highlights the core results concerning the advance booking $\left(\beta_{n t}\right)$ and competitor price effects $\left(\beta_{n n}\right)$, quantifying such relationships. Analysing the dynamic of a flight with respect to the booking date, one can observe that, as expected, booking last minute is more expensive for all types of travel (H1). However, the price difference with respect to booking in advance is maximum for low-cost carriers (64.8\% and $51.7 \%$ for Ryanair and Easyjet, respectively) and minimum in the case of Alitalia business and Italo business, supporting the idea that intensive dynamic revenue management is more common among the cheapest categories that offer advance-purchase discounts.

As to the competitors' effect on price, a positive sign suggests a potential substitution between the two categories: since competitors' prices are in log, the coefficients can be interpreted as elasticities. The coefficients describing intramodal competition are highlighted in light grey in the matrix. Alitalia business fares move independently, while low-cost carriers and the lowest Alitalia fare tend to have similar moves. Whereas, within-train competition also presents significant coefficients. Italo adjusts both its two tariffs to the corresponding class level of Frecciarossa, and the same strategic behaviour can be seen in the case of Frecciarossa standard. On the whole, these coefficients provide support to $\mathrm{H} 2$, but, as an anomaly, Frecciarossa business fare seems to depend on Italo standard fare rather than on the business one.

The results for intermodal competition (highlighted in dark grey) show some kind of asymmetric behaviour and provide further support to the presence of different revenue management strategies between trains and airlines $(\mathrm{H} 3)$. While train prices seem not to react significantly to airline ones, the prices of low-cost carriers seem to adjust depending on the moves of Italo. Also, the minimum available fare of Alitalia is significantly affected by both Frecciarossa business and Italo standard tariffs. Regarding the intermodal competition within similar target segments, the findings support $\mathrm{H} 2$ only partially. There are some cases where this hypothesis holds: the reaction of Ryanair, Easyjet and the 
minimum tariff of Alitalia to the Italo standard tariff. Nonetheless, there are other relationships that are more counterintuitive, like the effect of Italo business tariff on the Ryanair pricing strategy.

\section{Conclusion and limitations}

The adoption of revenue and yield management techniques is very popular in the tourism and travel industries and has been shown to have a positive effect on load factors (Bilotkach et al, 2015). Nonetheless, the way operators react to short-term competitors' price variations is relatively unexplored in the empirical literature. This paper attempts to fill this gap, providing a pricing regression model applied to the passenger transport market. Specifically, it focuses on the characteristics of intramodal and intermodal competition between airlines and high-speed trains. Advance-purchase discounts tend to be higher for low-cost products. In general, prices evolve coherently within the business and leisure segments, but with some exceptions. Finally, price competition tends to be asymmetric between trains and airlines, since only the latter appears to be reactive to competitors' price changes. These results suggest the adoption of heterogeneous pricing strategies depending on the different type of supplier. Interestingly, it appears that traditional carriers (Alitalia in our case) tend to move independently from low-cost airlines, while low-cost airlines are following them in their pricing strategies. This finding confirms the different supply strategies adopted to increase revenues.

Through an examination of the impact of our control variables on the empirical model, it appears that business-oriented operators generally present higher prices during weekdays and peak hours, while low-cost operators present higher prices during the weekend, consistently with tourism population preferences.

The travel and tourism arena has started to investigate the advantages of the adoption of dynamic pricing in different routes. Our contribution suggests that, to have a complete picture, the analysis has to investigate intramodal and intermodal options jointly when they are present, as travellers are generally flexible and willing to switch to another mode of transport (Ivaldi and Vibes, 2008; Behrens and Pels, 2012). On the whole, these interrelated results suggest the need for further studies to disentangle the complexity of relations between different modes in tourism and transport settings. As found in the hospitality industry by Lee and Jang (2013), revenue managers have to identify the best profit maximization strategy. This can be obtained by monitoring the decisions of competitors of similar quality and by accounting for asymmetric price dynamics in decision-making processes.

Studying only one route makes it possible to consider properly all sets of prices, which would be very difficult to gather for a large set of routes (Dobruszkes et al, 2014). Nonetheless, this study might raise the issue of representativeness in the complex relationships within and between modal competitions. Analysts and researchers need to improve the quality of prediction models when conducting research on a specific competition set. Based on a priori theory, the structural equation model would have allowed the measurement of indirect effects (Bentler, 2006). This is left for future research. 


\section{Notes}

1. Frecciarossa offers in addition some extra class differentiation: a 'Premium' option is available as an intermediate level between standard and business service, while among the business category it is possible to book the 'business silence area'. Moreover, Alitalia, Frecciarossa and Italo do offer some discount in case of 'return tickets' (on average, around 6-7\% of the oneway ticket); however, the dynamic of return ticket prices strictly follows the dynamic of oneway ticket prices.

2. When an alternative was not available in a particular time slot, in order to simulate such a 'scarcity' in the supply without losing observations, we considered the highest price for that travel type (actually, this mainly happened because Ryanair flights are not available in the central hours of the day).

\section{References}

Abrate, G., Fraquelli, G., and Viglia, G. (2012), 'Dynamic pricing strategies: evidence from European hotels', International Journal of Hospitality Management, Vol 31, No 1, pp 160-168.

Alderighi, M., Cento, A., and Piga, C.A. (2011), 'A case study of pricing strategies in European airline markets: the London-Amsterdam route', Journal of Air Transport Management, Vol 17, No 6, pp 369-373.

Behrens, C., and Pels, E. (2012), 'Intermodal competition in the London-Paris passenger market: high-speed rail and air transport', Journal of Urban Economics, Vol 71, No 3, pp 278-288.

Bentler, P.M. (2006), EQS 6 Structural Equation Program Manual, Multivariate Software, Encino, CA.

Bergantino, A.S., and Capozza, C. (2015), 'Airline pricing behaviour under limited intermodal competition', Economic Inquiry, Vol 53, No 1, pp 700-713.

Bilotkach, V., Gaggero, A.A., and Piga, C.A. (2015), 'Airline pricing under different market conditions: evidence from European low-cost carriers', Tourism Management, Vol 47, pp 152-163.

Bitran, G., and Caldentey, R. (2003), 'An overview of pricing models for revenue management', Manufacturing \& Service Operations Management, Vol 5, No 3, pp 203-229.

Bull, A.O. (2006), 'Industrial economics and pricing issues within tourism enterprises and markets', in Dwyer, L., and Forsyth, P., eds, International Handbook on the Economics of Tourism, Edward Elgar, Cheltenham, pp 138-154.

Castillo-Manzano, J.I., Pozo-Barajas, R., and Trapero, J.R. (2015), 'Measuring the substitution effects between rail and air transport in Spain', Journal of Transport Geography, Vol 43, pp 59-65.

Chiang, W.C., Chen, J.C., and Xu, X. (2007), 'An overview of research on revenue management: current issues and future research', International Journal of Revenue Management, Vol 1, No 1, pp $97-128$.

Dana, J.D. (1998), 'Advance-purchase discounts and price discrimination in competitive markets', Journal of Political Economy, Vol 106, No 2, pp 395-422.

Delaplace, M., and Dobruszkes, F. (2015), 'From low-cost airlines to low-cost high-speed rail? The French case', Transport policy, Vol 38, pp 73-85.

Dennis, N. (2007), 'End of the free lunch? The responses of traditional European airlines to the low-cost carrier threat', Journal of Air Transport Management, Vol 13, No 5, pp 311-321.

Dobruszkes, F., Dehon, C., and Givoni, M. (2014), 'Does European high-speed rail affect the current level of air services? An EU-wide analysis', Transportation Research Part A: Policy and Practice, Vol 69, pp 461-475.

Gaggero, A.A. (2010), Airline Pricing and Competition: The J-curve of Airline Fares, Lambert Academic Publishing, Saarbrücken.

Gallego, G., and van Ryzin, G. (1994), 'Optimal dynamic pricing of inventories with stochastic demand over finite horizons', Management Science, Vol 40, No 8, pp 999-1020.

Haws, K., and Bearden, W.O. (2006), 'Dynamic pricing and consumer fairness perceptions', Journal of Consumer Research, Vol 33, pp 304-311.

Heo, C.Y., and Lee, S. (2011), 'Influences of consumer characteristics on fairness perceptions of revenue management pricing in the hotel industry', International Journal of Hospitality Management, Vol 30, No 2, pp 243-251.

Holloway, J.C., and Taylor, N. (2006), The Business of Tourism, Pearson Education, Harlow.

Ivaldi, M., and Vibes, C. (2008), 'Price competition in the intercity passenger transport market: a simulation model', Journal of Transport Economics and Policy, Vol 42, No 2, pp 225-254. 
Jeng, C.R., and Su, C.H. (2013), 'The predicament of domestic airline service after the introduction of Taiwan high-speed rail', Transportation Journal, Vol 52, No 1, pp 134-143.

Jung, S.Y., and Yoo, K.E. (2014), 'Passenger airline choice behavior for domestic short-haul travel in South Korea', Journal of Air Transport Management, Vol. 38, pp 43-47.

Kim, J.Y., Natter, M., and Spann, M. (2009), 'Pay what you want: a new participative pricing mechanism', Journal of Marketing, Vol 73, No 1, pp 44-58.

Lee, S.K., and Jang, S.S. (2013), 'Asymmetry of price competition in the lodging market', Journal of Travel Research, Vol 52, No 1, pp 56-67.

Luo, L., and Peng, J.H. (2007), 'Dynamic pricing model for airline revenue management under competition', Systems Engineering-Theory \& Practice, Vol 27, No 11, pp 15-25.

Mumbower, S., Garrow, L.A., and Higgins, M.J. (2014), 'Estimating flight-level price elasticities using online airline data: a first step toward integrating pricing, demand, and revenue optimization', Transportation Research Part A: Policy and Practice, Vol 66, pp 196-212.

Narangajavana, Y., Garrigos-Simon, F., Sanchez García, J., and Forgas-Coll, S. (2014), 'Prices, prices and prices: a study in the airline sector', Tourism Management, Vol 41, pp 28-42.

Netessine, S., and Shumsky, R.A. (2005), 'Revenue management games: horizontal and vertical competition', Management Science, Vol 51, No 5, pp 813-831.

O'Connell, J.F., and Williams, G. (2005), 'Passengers' perceptions of low cost airlines and full service carriers: a case study involving Ryanair, Aer Lingus, Air Asia and Malaysia Airlines', Journal of Air Transport Management, Vol 11, No 4, pp 259-272.

Pan, Q., Richardson, H.W., Park, J., Gordon, P., and Moore II, J.E. (2015), 'Peak load road pricing: potential impacts on Los Angeles', in Pan, Q., Richardson, H.W., Park, J., Gordon, P., and Moore II, J.E., eds, Regional Economic Impacts of Terrorist Attacks, Natural Disasters and Metropolitan Policies, Springer International Publishing, Berlin, pp 195-204.

Park, Y., and Ha, H.-K. (2006), 'Analysis of the impact of high-speed railroad service on air transport demand', Transportation Research, Vol 42, No 2, pp 95-104.

Piga, C.A., Alderighi, M., and Nicolini, M. (2015), 'Combined effects of capacity and time on fares: insights from the yield management of a low-cost airline', Review of Economics and Statistics, Vol 97, No 4, pp 900-915.

Roman, C., Espino, R., and Martin, C. (2007), 'Competition of high-speed train with air transport: the case of Madrid-Barcelona', Journal of Air Transport Management, Vol 13, pp 277-284.

Ropero García, M.A. (2013), 'Effects of competition and quality on hotel pricing policies in an online travel agency', Tourism Economics, Vol 19, No 1, pp 63-76.

Rosselló, J., and Riera, A. (2012), 'Pricing European package tours: the impact of new distribution channels and low-cost airlines', Tourism Economics, Vol 18, No 2, pp 265-279.

Schwartz, Z., Stewart, W., and Backlund, E.A. (2012), 'Visitation at capacity-constrained tourism destinations: exploring revenue management at a national park', Tourism Management, Vol 33, No 3 , pp 500-508.

Stavins, J. (2001). 'Price discrimination in the airline market: the effect of market concentration', Review of Economics and Statistics, Vol 83, No 1, pp 200-202.

Tsai, W., and Hung, S. (2009), 'Dynamic pricing and revenue management process in Internet retailing under uncertainty: an integrated real options approach', Omega: the International Journal of Management Science, Vol 37, No 2, pp 471-481.

Uvet (2015), 'Business travel survey 2015' (http://www.uvetamex.com/media/172050/UvetAmex_ BTSurvey_febbraio_2015.pdf, accessed 4 April 2015).

Vinod, B. (2005), 'Alliance revenue management', Journal of Revenue and Pricing Management, Vol 4, No 1, pp 66-82.

Wang, Y., Li, L., Wang, L., Moore, A., Staley, S., and Li, Z. (2014), 'Modeling traveler mode choice behavior of a new high-speed rail corridor in China', Transportation Planning and Technology, Vol 37, No 5, pp 466-483. 